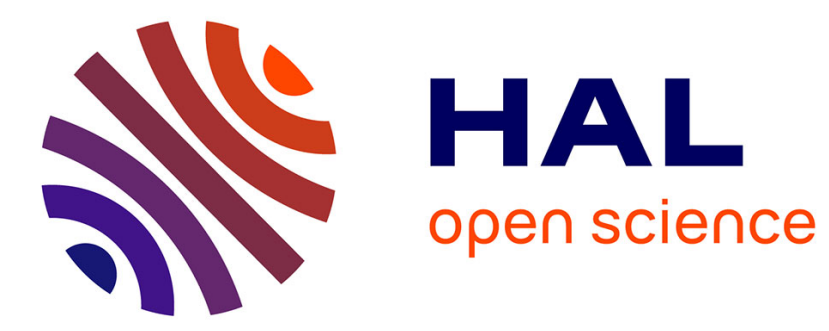

\title{
Manual laterality for pointing gestures compared to grasping actions in guenons and mangabeys
}

Audrey Maille, Amandine Chapelain, Laure Déruti, Philippe Bec, Catherine Blois-Heulin

\section{- To cite this version:}

Audrey Maille, Amandine Chapelain, Laure Déruti, Philippe Bec, Catherine Blois-Heulin. Manual laterality for pointing gestures compared to grasping actions in guenons and mangabeys. Animal Behaviour, 2013, 86 (4), pp.705-716. 10.1016/j.anbehav.2013.06.016 . hal-00865380

HAL Id: hal-00865380

https://hal-univ-rennes1.archives-ouvertes.fr/hal-00865380

Submitted on 24 Sep 2013

HAL is a multi-disciplinary open access archive for the deposit and dissemination of scientific research documents, whether they are published or not. The documents may come from teaching and research institutions in France or abroad, or from public or private research centers.
L'archive ouverte pluridisciplinaire $\mathbf{H A L}$, est destinée au dépôt et à la diffusion de documents scientifiques de niveau recherche, publiés ou non, émanant des établissements d'enseignement et de recherche français ou étrangers, des laboratoires publics ou privés. 


\title{
Manual laterality for pointing gestures compared to grasping actions in guenons and mangabeys.
}

Audrey Maille*, Amandine Chapelain, Laure Déruti, Philippe Bec, Catherine Blois-Heulin Ethos 'Ethologie Animale et Humaine', Université de Rennes 1 - CNRS UMR 6552, Station biologique de Paimpont, France

Received 19 November 2012

Initial acceptance 25 January 2013

Final acceptance 5 June 2013

MS. number: 12-00864R

\author{
*Correspondence: A. Maille, UMR 6552, Station Biologique, Université de Rennes 1, 35380 \\ Paimpont, France. \\ E-mail: maille.aud@gmail.com (A. Maille).
}

In both humans and apes, the production of communicative gestures appears to be controlled by cerebral structures in the left hemisphere that would be distinct from those involved in noncommunicative actions. Whether communicative gestures also rely on specific lateralized systems in monkeys remains unclear. We assessed manual laterality for requesting gestures, thatwere pointing, and for grasping actions in two species of Old World monkeys, Campbell's monkeys, Cercopithecus campbelli, and red-capped mangabeys, Cercocebus torquatus, using the Bishop QHP task. The food items were placed at five positions in front of the monkeys and they were located at out-of-reach, far or close distance from the monkeys, to induce pointing gestures and grasping actions requiring full or low arm extensions, respectively. The 
mangabeys that exhibited the greatest skills for pointing referentially were more right-handed for pointing gestures than for grasping actions. We propose that in Old World monkeys, as in humans and apes, the production of intentional and referential gestures may rely on the activation of specific regions of the left hemisphere specialized in the processing of communicative signals. Subjects from both species preferred to use the hand that was closest to the item for grasping actions requiring low arm extension whereas they used the contralateral hand for grasping actions requiring full arm extension and pointing gestures. These results are discussed in relation to hypotheses on postural control and arboreality.

\section{KEYWORDS}

Broca's homologue, Campbell's monkey, Cercocebus torquatus, Cercopithecus campbelli. communicative signal, hand preference, hemispheric specialization, red-capped mangabey.

In humans, communicative gestures are mainly performed by the right hand, whether they are co-speech gestures (gesticulation: Kimura 1973a, b), referential gestures (pantomime and emblem including pointing gesture: Blake et al. 1994; Bates \& Dick 2002; Butterworth 2002; Vauclair \& Imbault 2009; Cochet \& Vauclair 2010a) or language-like gestures (sign language: Bonvillian et al. 1997; Hickok et al. 1998). The production of gestures has been shown to engage the same cerebral structures in the left hemisphere as spoken language: Broca's area (Corina et al. 1993; Horwitz et al. 2003; Skipper et al. 2007; Xu et al. 2009) and 
Wernicke's areas (Corina et al. 1992). This suggests that the left hemisphere would be specialized in communicative activities, regardless of whether the modality was vocal and/or gestural. Recently, Xu et al. (2009, page 3) proposed that Broca's area and Wernicke's area "do not constitute a language network per se but function as a general modality-independent system that support symbolic communication".

Nonhuman primates, like humans, use communicative gestures in a wide range of social contexts (Call \& Tomasello 2007a). In the last few years, similarities between apes and humans have been revealed in laterality for manual gestures. First, right-hand populationlevel biases for the production of manual gestures have been reported in several studies (chimpanzees, Pan troglodytes: Hopkins \& Wesley 2002; Hopkins \& Cantero 2003; Hopkins et al. 2005; Meguerditchian et al. 2010, 2012; bonobos, Pan paniscus: Hopkins \& de Waal 1995; Shafer 1997; gorillas, Gorilla gorilla: Hopkins et al. 2012). Second, hand preferences for manual gestures have been found to be linked to leftward asymmetries in cortical regions that are homologous to Broca's area (i.e. inferior frontal gyrus: Hopkins \& Cantalupo 2004; Taglialatela et al. 2006; Cantalupo \& Hopkins 2010; Meguerditchian et al. 2012) and Wernicke's area (i.e. planum temporale: Hopkins \& Nir 2010). Finally, the left inferior frontal gyrus has been shown to be activated during the production of communicative manual gestures (Taglialatela et al. 2008. 2011).

Communicative and manipulative activities seem to be controlled by distinct cerebral structures in both humans and nonhuman apes. Right-hand use has indeed been shown to be greater for communicative gestures compared to grasping (humans: Cochet \& Vauclair 2010b; Esseily et al. 2010) and manipulative actions (humans: Bonvillian et al. 1997; chimpanzees: Hopkins et al. 2005; Meguerditchian et al. 2010). Moreover, several studies found no relationship between the direction of hand preferences for communicative and noncommunicative activities in either human children (Bonvillian et al. 1997; Cochet \& 
Vauclair 2010b; Esseily et al. 2010; Cochet 2012; Cochet et al. 2011) or chimpanzees (Hopkins \& Leavens 1998; Hopkins \& Wesley 2002; Hopkins \& Cantero 2003; Meguerditchian et al. 2012).

Studies on monkeys' gestures may have strong implications for understanding the evolutionary origins of hemispheric specialization for language. Currently, it is unclear whether communicative gestures also involve specific lateralized systems in monkeys. As far as we know, hand preferences for gestures have been investigated in only one species of Old World monkey, the olive baboon, Papio anubis. In this species, a right-hand bias was found for the production of a threat gesture, the 'hand slap', and the pattern of laterality differed from that reported for grasping actions and manipulative actions (Meguerditchian \& Vauclair 2006; Meguerditchian et al. 2011). To test whether the left-hemisphere specialization for communicative activities found in human and nonhuman apes is conserved in more distant relatives, there is a need to enlarge the investigation of laterality for manual gestures in several monkey species.

In the present study, we focused on requesting gestures, which are imperative manual gestures directed towards a desired item (Leavens 2004) such as begging and pointing gestures, produced by nonhuman primates towards humans. On the one hand, one may hypothesize that monkeys' requesting gestures differ from those of apes in their communicative functions. Indeed, a gap divides monkeys from apes in their production of requesting gestures: apes often produce requesting gestures towards either conspecifics or humans (Call \& Tomasello 2007b) whereas, to our knowledge, monkeys have never been observed to produce requesting gestures towards conspecifics. Moreover, in contrast to apes, captive monkeys must generally be trained to produce requesting gestures (Gómez 2005). Yet, we believe that requesting gestures of trained monkeys are efficient communicative signals since monkeys seem to be able to use requesting gestures to communicate 
intentionally with human recipients. Several studies indeed suggest that requesting gestures of monkeys would be mostly directed towards an attentive human audience (squirrel monkeys, Saimiri sciureus: Anderson et al. 2010; capuchin monkeys, Cebus apell a: Hattori et al. 2010; red-capped mangabeys, Cercocebus torquatus: Maille et al. 2012; olive baboons: Meunier et al. 2013). On the other hand, one may argue that it is not relevant to investigate manual laterality within the scope of interspecific gestural communication. Manual laterality for communicative gestures may indeed differ according to whether the gesture is directed towards a conspecific or a human recipient. However, some studies have pointed out that chimpanzees exhibit a right-hand bias for the production of communicative gestures, regardless of whether they produce gestures towards conspecifics or humans (e.g. begging gestures: Meguerditchian et al, 2010; clapping gestures: Meguerditchian et al. 2012). We thus assume that requesting gestures directed towards humans would be controlled by the same cerebral structures as communicative gestures directed towards conspecifics, in monkeys as in nonhuman apes.

The requesting gestures of monkeys consist of full arm extensions (Gómez 2005) but the existing literature has only compared requesting gestures of monkeys to grasping of items located near to the subjects, thus requiring low arm extensions (baboons: Meguerditchian \& Vauclair 2009; Meunier et al. 2012). We aimed to compare manual laterality in monkeys for requesting gestures and for grasping actions requiring either full or low arm extensions. We hypothesized that (1) monkeys, like humans and nonhuman apes, would use their right hand more frequently for pointing gestures than for grasping actions, (2) right-hand use for pointing gestures would be greater in monkeys showing better communicative abilities and (3) hand preferences for pointing gestures and for grasping actions requiring full arm extensions would be similarly affected by the position of the items because these two arm movements share the same motor pattern. 
To compare the respective patterns of hand preferences for pointing gestures and for grasping actions, we devised an experimental design in which the posture of the subject, the position of the items to request/grasp and the distance from the subject to the items were standardized. The 'quantification of hand preferences' task (QHP task: Bishop et al. 1996) was first designed to measure handedness in human participants for grasping actions towards items that are presented in several locations in front of them. The QHP task has been successfully adapted for monkeys using food items (Meunier et al. 2011; Chapelain et al. 2012). Moreover, this task has been previously used to compare handedness for pointing gestures and for grasping actions requiring low arm extensions in humans (infants: Jacquet et al. 2012; Meunier et al. 2012; adults: Calvert \& Bishop 1998) and baboons (Meunier et al. 2012). The QHP task thus appears suitable for investigating hand preferences for pointing gestures compared to grasping actions in human and nonhuman primates.

In this study, we investigated manual laterality for requesting gestures and for grasping actions in two genera of Old World monkeys that are closely related to baboons: Cercopithecus (guenons) and Cercocebus (one genus of mangabeys). We chose to study Campbell's monkeys, Cercopithecus campbelli, and red-capped mangabeys, Cercocebus torquatus, because, in contrast to humans and baboons, which are both terrestrial species, Campbell's monkeys are arboreal (Oates 1988) and red-capped mangabeys are semiterrestrial (Gautier-Hion et al. 1999). These variations in habitat may affect manual laterality in nonhuman primates. MacNeilage $(1993,2007)$ hypothesized that arboreal primates should be more left-handed than terrestrial primates because of a right-hand specialization for postural support in the trees. Moreover, Rogers \& Kaplan (1996) suggested that an arboreal lifestyle may induce a decrease in manual asymmetries because of a need to adapt to the architecture 
of the trees: to grasp food items safely in the trees, one hand must be used to hang on to the branches while the other hand grasps the food items.

In both guenons and mangabeys, we compared manual laterality for pointing gestures and grasping actions and we evaluated the influence of the position of the items on the hand used to request/grasp. Therefore, we used three versions of the QHP task to measure manual laterality for pointing gestures and for grasping actions requiring either full or low arm extensions. When the food items were located on the subject's body midline, we predicted that both guenons and mangabeys would be more right-handed for pointing gestures than for grasping actions and that there would be no relationship between the hand preferences exhibited for pointing gestures compared to grasping actions. Moreover, we predicted that the subjects showing the greatest skills for directing their pointing gestures towards hidden items located at one of five potential positions would be more right-handed for the production of pointing gestures than the other subjects. Finally, when the items were located away from the subject's body midline, we postulated that there would be a predominant use of the ipsilateral hand to the food items for both pointing gestures and grasping actions requiring full or low arm extensions.

\section{$<$ H1 $>$ METHODS}

\section{$<H 2>$ Subjects}

Experimental subjects were 12 adult Campbell's monkeys (three males and nine females) and 16 adult or juvenile red-capped mangabeys (eight males and eight females; Table 1). All subjects were housed at the Station Biologique de Paimpont (Université de 
Rennes 1, France). They lived in social groups, in cages composed of indoor and outdoor enclosures of various sizes (indoor enclosures: minimum: $9 \mathrm{~m}^{2}$ and $3.70 \mathrm{~m}$ high, maximum: $26 \mathrm{~m}^{2}$ and $3.70 \mathrm{~m}$ high; outdoor enclosures: minimum: $12 \mathrm{~m}^{2}$ and $4 \mathrm{~m}$ high, maximum: 330 $\mathrm{m}^{2}$ and $4.50 \mathrm{~m}$ high). Food was given twice a day (fresh fruits and vegetables in the morning, monkey chows in the afternoon) and water was available ad libitum. Climbing furniture, ground substrates (woodchips and straw) and sunflower seeds were provided as enrichment on a daily basis. Experiments were conducted in cages adjacent to the home cages of subjects. The subject being tested was isolated from dominant conspecifics and could move freely during the test. All of the subjects were habituated to being tested and isolated. Subjects were not deprived of food or water during testing. The experiment was conducted between February 2011 and May 2011 in guenons and between September 2010 and January 2011 in mangabeys.

The experiment was licensed by the departmental direction of veterinary services of Ille-etVilaine (licence no. 04672) in accordance with the European Communities Council Directive of 24 November 1986 (86/609/EEC). Animal facilities and animal care procedures were regularly monitored by the responsible local authorities, while animal husbandry and care were under management of the staff of the biological station in Paimpont, University of Rennes 1, France. During the experiments, animals were constantly monitored for signs of distress and care was taken to provide a stress-free experimental environment.

\section{$<H 2>$ Experimental design}

A semicircular board (guenons: PVC Celuka, diameter $=120 \mathrm{~cm}$, thickness $=1 \mathrm{~cm}$; mangabeys: wood covered with zinc-plated steel, diameter $=160 \mathrm{~cm}$, thickness $=2 \mathrm{~cm}$; Fig. 1) was attached horizontally onto the wire-net mesh outside the cage (distance between the 
board and the ground: guenons: $120 \mathrm{~cm}$; mangabeys: $80 \mathrm{~cm}$ ). Five positions were marked on the board, each separated by $30^{\circ}$ from one another (Fig. 1). The positions were labelled according to their angle with the midline from the subject's point of view: leftward positions $\mathrm{LL}\left(-60^{\circ}\right)$ and $\mathrm{L}\left(-30^{\circ}\right)$, central position $\mathrm{C}\left(0^{\circ}\right)$, rightward positions $\mathrm{R}\left(+30^{\circ}\right)$ and $\mathrm{RR}\left(+60^{\circ}\right)$. Conversely to the original QHP task (Bishop 1996), we did not use the two extreme positions (i.e. $-90^{\circ}$ and $+90^{\circ}$ ) because of physical constraints linked to the cage mesh.

A rectangular opening in the wire-net mesh at the board level (guenons: $28 \times 6 \mathrm{~cm}$; mangabeys: $44 \times 8 \mathrm{~cm}$ ) allowed the subjects to pass their arms through the mesh and move their arms freely over the board (Fig. 1). A stool (wood and zinc-plated steel: $47 \times 42 \times 3 \mathrm{~cm}$ ) was fixed onto the wire-net mesh inside the cage, just in front of the board centre. When seated on the stool, the subjects were in a frontal position relative to the board. The stool was removable and the distance between the stool and the board varied according to the size of the subject so as to ensure that the elbows of the subjects were at the same level as the board (guenons: males: $28 \mathrm{~cm}$; females: $24 \mathrm{~cm}$; mangabeys: males $<5$ years: $28 \mathrm{~cm}$; males $>5$ years: $36 \mathrm{~cm}$; females $<4$ years: $20 \mathrm{~cm}$; females $>4$ years: $28 \mathrm{~cm}$ ).

\section{$<H 2>$ Experimental procedure}

For each trial, a food item was placed at one of the five positions that were marked on the board (Fig. 1); the hand used by the experimenter to place the food item was chosen at random. We used various food items (sunflower seeds, raisins, peanuts and pistachios) according to the preference of the subject. We exposed the subjects to three experimental tasks: the QHP-Pointing task (QHP-P), the QHP-Far Grasping task (QHP-FG) and the QHPNearby Grasping task (QHP-NG). For each of the three tasks, the trials began when the subject was sitting on the stool with its arms placed symmetrically. Two experimenters (E1 
and E2) participated in the QHP-P task whereas only one experimenter (E1) was involved in the QHP-FG and the QHP-NG tasks.

Each test session consisted of a total of 25 trials, five trials in each of the five positions, which were presented in a random order (the same for all subjects and every experimental task). Every subject participated in 12 test sessions for each task, for a total of 300 trials per task (60 trials per position). The tasks were performed in the following order: QHP-NG, QHP-FG and QHP-P tasks in guenons, and QHP-NG, QHP-P and QHP-FG tasks in mangabeys. We performed only one session per day for each subject.

\section{$<H 3>Q H P-P o i n t i n g$ task}

In the QHP-P task, the food items were out of reach for the subject. The distance between the centre of the board and the items varied according to the length of the arm of the subject (guenons: males: $45 \mathrm{~cm}$; females: $38 \mathrm{~cm}$; mangabeys: males $<5$ years: $52 \mathrm{~cm}$; males $>5$ years: $65 \mathrm{~cm}$; females $<4$ years: $45 \mathrm{~cm}$; females $>4$ years: $55 \mathrm{~cm}$ ). Five opaque tubes (zinc-plated steel: diameter: $4 \mathrm{~cm}$, length: $7 \mathrm{~cm}$; thickness: $0.1 \mathrm{~cm}$ ) were placed vertically on the board, one tube per position (Fig. 1). The food items were hidden under the tubes to prevent the subject from seeing them. At the beginning of each trial, one experimenter, E1, stood with her back turned to the subject and the other experimenter, E2, stood facing the subject. The trials were divided into the following three phases.

(1) Baiting phase: E2 showed the food item to the subject. She then lifted an opaque tube (position chosen at random) to place and hide the item underneath it. She finally repositioned the tube in its original location. E1 remained blind to the baiting phase.

(2) Transition phase: E2 waited until the subject stopped producing pointing gestures and positioned its arms symmetrically. E2 then turned her back to the subject while E1 turned around to face the subject. 
(3) Pointing phase: E1 looked at the subject. As soon as the subject extended one or both arms towards a tube (i.e. pointing gesture), E1 lifted the indicated tube. If the subject succeeded, that is, if it produced a pointing gesture towards the baited tube, E1 gave the food item to the subject. If the subject failed, that is, if it produced a pointing gesture towards an unbaited tube, E1 looked inside the other tubes and took away the food item from the baited tube. If the subject did not produce any pointing gestures within $30 \mathrm{~s}$, E1 acted as if the subject had failed.

A training programme was conducted before the QHP-P task in both species because it was necessary to train monkeys to produce pointing gestures towards some tubes. During the training programme, whenever the subjects started to extend one or both arms towards the location of a food item, E1 immediately gave them the food item. At first (step 1), the food item was visible and later (step 2) it was hidden under one of two tubes. Each subject was trained during 15 min daily sessions. The training programme was considered completed for a subject when it was successful in at least five trials (i.e. pointing gesture directed towards the food item) per position in each step.

\section{$<H 3>Q H P-F a r$ Grasping task}

In the QHP-FG task, the food items were placed far from the subject (for both arms): subjects had to perform a full arm extension in order to grasp the items. The distance between the centre of the board and the food items varied according to the length of the arm of the subject (guenons: males: $30 \mathrm{~cm}$; females: $23 \mathrm{~cm}$; mangabeys: males $<5$ years: $32 \mathrm{~cm}$; males $>5$ years: $45 \mathrm{~cm}$; females < 4 years: $25 \mathrm{~cm}$; females $>4$ years: $35 \mathrm{~cm}$ ). At the beginning of each trial, E1 stood facing the subject. 
In the QHP-NG task, the food items were placed close to the subject (for both arms). The distance between the centre of the board and the food items varied according to the length of the arm of the subject (guenons: males: $15 \mathrm{~cm}$; females: $15 \mathrm{~cm}$; mangabeys: males $<5$ years: $20 \mathrm{~cm}$; males $>5$ years: $25 \mathrm{~cm}$; females < 4 years: $15 \mathrm{~cm}$; females $>4$ years: $20 \mathrm{~cm}$ ). At the beginning of each trial, E1 stood facing the subject.

$<H 2>$ Data scoring

In the QHP-P task, we scored the first pointing gesture directed towards an opaque tube during the pointing phase of each trial (i.e. when E1 was facing the subject). We did not score the pointing gestures produced during the baiting and the transition phases of each trial (i.e. when E2 was facing the subject) because E2 knew where the food item was hidden and could thus provide information about its location to the subject during gesture production. We recorded (1) which arm (left or right arm, or both arms) was used to perform the pointing gesture and (2) the position of the opaque tube indicated by the pointing gesture. We usually recorded more or less than 60 trials per position because some pointing gestures were directed towards a tube other than the baited one.

In the QHP-FG and the QHP-NG tasks, we recorded which arm (left or right arm) was used to grasp the food item on each trial.

All test sessions were videotaped and later coded by E1. The videorecords were analysed by E1 using a VLC Media Player.

$<H 2>$ Data analysis 
We calculated an individual handedness index (HI) per position and per subject in each experimental task. HI was calculated using the formula: $\mathrm{HI}=$ (number of right - number of left $) /($ number of right + number of left). HI varies between -1 and +1 and gives the direction of hand preference: negative values indicate a bias towards a preference for the left hand and positive values indicate a bias towards a preference for the right hand. When calculating HI values from the QHP-P task, (1) we did not consider trials in which pointing gestures were performed bimanually (mean \pm SE per position: guenons: $1.0 \pm 0.7$; mangabeys: $6.1 \pm 2.8$ ) and (2) we considered trials in which pointing gestures were directed towards an opaque tube other than the baited one (mean \pm SE per position: guenons: $9.7 \pm 2.1$; mangabeys: $11.8 \pm 2.4$ ) but we allocated these trials to the pointed tube's position rather than to the baited tube's position.

\section{$<H 3>$ Manual laterality for pointing gestures compared to grasping actions}

We determined whether subjects were left-handed or right-handed at each position and for each experimental task using the binomial test on the number of left and right actions. We assessed population-level biases in hand preference at each position using (1) the binomial test on the number of left- and right-handers and (2) the one-sample $t$ test on HI values.

We tested whether manual laterality at each position was consistent between the three experimental tasks using the Pearson correlation test with FDR (false discovery rate) correction on $\mathrm{HI}$ values.

\section{$<$ H3> Manual laterality in homogeneous and heterogeneous pointers}

In the QHP-P task, we expected subjects to produce pointing gestures equally towards each of the five positions. Indeed, we performed an equivalent number of trials per position (i.e. each of the five opaque tubes was baited on 60 trials randomly distributed in the test 
sessions) and all the subjects were successfully trained to produce referential pointing, that is, pointing gestures directed towards the baited opaque tube. In each subject, we assessed homogeneity in the number of pointing gestures directed towards each of the five opaque tubes using the chi-square test: a statistical significance revealed a lack of homogeneity, i.e. under- or overrepresentation of trials for which the pointing gestures were directed towards a given container (usually referred to as 'position bias': e.g. Jolly 1964). We classified subjects into two pointer categories: heterogeneous pointers (chi-square significant) and homogeneous pointers (chi-square not significant); we assumed that homogeneous pointers exhibited the greatest skills for pointing referentially compared to heterogeneous pointers. We tested whether HI values differed between the two pointer categories using repeated measures ANOVA on HI values.

\section{$<H 3>$ Influence of the position of items on manual laterality}

We assessed whether manual laterality differed between the two species and whether it was affected by the task or the position of the food items using repeated measures ANOVA on $\mathrm{HI}$ values. We analysed the correlation between $\mathrm{HI}$ values and the numbers of the positions $(\mathrm{LL}=1, \mathrm{~L}=2, \mathrm{C}=3, \mathrm{R}=4, \mathrm{RR}=5)$ using Pearson correlation tests to evaluate more precisely the influence of the position on manual laterality.

Finally, we analysed the potential influence of the adult subjects' sex on the manual laterality exhibited for each of the three QHP tasks using repeated measures ANOVA and Pearson correlation tests on HI values.

We checked for equivariance and normality of the residuals of the ANOVAs. We used paired $t$ tests with FDR correction as post hoc tests. Statistical tests were two tailed and type I error $\alpha$ was set at 0.05 . All analyses were performed with R 2.14.2 (The R Foundation for 
Statistical Computing, Vienna, Austria, http://www.r-project.org); when statistical tests yielded nonsignificant results, post hoc statistical power was calculated with GPower 3.1 (Faul et al. 2007).

\section{$<$ H1 $>$ RESULTS}

The number of pointing gestures or grasping actions performed with either the left hand or the right hand by each subject as well as the individual hand preferences and the HI values are reported in Table 2 (data for the central position for the three tasks) and in Appendix Tables A1, A2 and A3 (data for the four lateral positions for the QHP-P task, QHPFG task and QHP-NG task, respectively).

$<$ H2>Manual laterality for pointing gestures compared to grasping actions

\section{$<$ H3>Hand preferences (central position)}

For pointing gestures (QHP-P task) directed towards the central position $\mathrm{C}$, the mean $\mathrm{HI}$ was $0.33(\mathrm{SE}=0.22)$ in guenons and $-0.12(\mathrm{SE}=0.21)$ in mangabeys. The analysis of $\mathrm{HI}$ values showed no significant group-level biases for the production of pointing gestures in either guenons (one-sample $t$ test: $t_{11}=1.52, P=0.158$, effect size $d=0.44$, power $=0.28$ ) or mangabeys (one-sample $t$ test: $t_{15}=-0.59, P=0.567, d=-0.15$, power $=0.09$ ). Moreover, there were no significant differences in the number of left- and right-handed subjects in either species (binomial test: guenons: $N=12, P=0.344$; mangabeys: $N=16, P=0.774$; Table 2).

For grasping items placed at the central position $\mathrm{C}$, the mean $\mathrm{HI}$ was $0.28(\mathrm{SE}=0.15)$ in guenons and $-0.21(\mathrm{SE}=0.16)$ in mangabeys for the QHP-FG task, whereas the mean HI was $0.21(\mathrm{SE}=0.13)$ in guenons and $-0.22(\mathrm{SE}=0.17)$ in mangabeys for the QHP-NG task. The 
analysis of HI values showed no significant group-level biases for the production of grasping actions requiring either full or low arm extensions in guenons (one-sample $t$ test: QHP-FG: $t_{11}$ $=1.82, P=0.096, d=0.52$, power $=0.38$; QHP-NG: $t_{11}=1.59, P=0.140, d=0.46$, power $=$ 0.22 ) and in mangabeys (one-sample $t$ test: QHP-FG: $t_{15}=-1.28, P=0.221, d=-0.32$, power $=0.31$; QHP-NG: $t_{15}=-1.21, P=0.243, d=-0.30$, power $\left.=0.21\right)$. Moreover, there were no significant differences in the number of left- and right-handed subjects for the QHP-FG task (binomial test: guenons: $N=12, P=0.180$; mangabeys: $N=16, P=0.581$; Table 2) and the QHP-NG task (binomial test: guenons: $N=12, P=0.289$; mangabeys: $N=16, P=0.388$; Table 2).

\section{$<H 3>$ Consistency in manual laterality}

HI values from the QHP-P task and the QHP-FG task were not significantly correlated in the two species (Pearson correlation test: $P>0.05$; detailed in Table 3), except at the two rightward positions $\mathrm{R}$ and $\mathrm{RR}$ in mangabeys ( Pearson correlation test: $P<0.05$; detailed in Table 3). Moreover, there were no significant correlations between HI values from the QHP-P task and the QHP-NG task, for all positions and species (Pearson correlation test: $P>0.05$; detailed in Table 3).

In contrast, there were significant positive correlations between HI values from the QHP-FG task and the QHP-NG task at positions L, C and R in mangabeys (and at position LL in guenons ((Pearson correlation test: $P<0.05$; detailed in Table 3$)$.

$<$ H2>Manual laterality in homogeneous and heterogeneous pointers

In guenons, the chi-square test classified ten subjects (83.3\%) as homogeneous pointers and two subjects $(16.7 \%)$ as heterogeneous pointers (Table 1). In mangabeys, the chi-square 
test classified seven subjects $(43.8 \%)$ as homogeneous pointers and nine subjects $(56.2 \%)$ as heterogeneous pointers (Table 1). We could thus compare manual laterality of homogeneous and heterogeneous pointers only in mangabeys.

A mixed ANOVA on HI values of mangabeys as a function of task and pointer category did not reveal a pointer category effect (ANOVA: $F_{1,15}=0.18, P=0.676$, effect size $f=0.11$, power $=0.07$ ) but it detected a task* pointer category interaction (ANOVA: $F_{2,30}=7.21, P<$ $0.001, f=0.37)$. First, we conducted a mixed ANOVA on HI values as a function of pointer category for each task separately. This analysis showed that homogeneous pointers were more right-handed than heterogeneous pointers in the QHP-P task (ANOVA: $F_{1,15}=4.68, P=$ 0.048, $f=0.58$; Fig. 2) whereas manual laterality did not differ between the two pointer categories for the QHP-FG task (ANOVA: $F_{1,15}=0.01, P=0.924, f=0.03$, power $=0.05$; Fig. 2) and the QHP-NG task (ANOVA: $F_{1,15}=0.75, P=0.402, f=0.23$, power $=0.14$; Fig. 2). Second, we performed a mixed ANOVA on HI values as a function of task in each pointer category. We found a main effect of task in homogeneous pointers (ANOVA: $F_{2,34}=11.61$, $P<0.001, f=0.49)$ : homogeneous pointers used their right hand more often for the QHP-P task than for the QHP-FG task (paired $t$ test: $P=0.021$; Fig. 2) and the QHP-NG task (paired $t$ test: $P<0.001$; Fig. 2). In contrast, no task effect was detected in heterogeneous pointers (ANOVA: $F_{2,30}=2.55, P=0.083, f=0.20$, power $=0.07$ ).

$<H 2>$ Influence of the position of items on manual laterality.

A mixed ANOVA on HI values as a function of species, task and position showed a significant main effect of the species (ANOVA: $F_{1,27}=4.73, P=0.039, f=0.42$ ): guenon subjects were more right-handed than mangabey subjects. However, we performed the following analyses in both species pooled together because there was no species*task 
interaction (ANOVA: $F_{2,54}=0.52, P=0.593, f=0.05$, power $=0.05$ ) and no species*position interaction (ANOVA: $F_{4,108}=2.01, P=0.093, f=0.15$, power $=0.06$ ) indicating that the species effect occurred similarly in the three tasks and among the five positions. The analysis revealed a task*position interaction (ANOVA: $F_{8,216}=18.72, P<$ $0.001, f=0.64)$

We conducted a mixed ANOVA analysis on HI values as a function of task at each position separately to assess how manual laterality differed between the three tasks. The analysis did not reveal a task effect at the central position (ANOVA: position C: $F_{2,54}=0.27$, $P=0.766, f=0.10$, power $=0.06$ ). However, it showed a significant main effect of the task at the four lateral positions (ANOVA: position LL: $F_{2,54}=30.29, P<0.001, f=1.07$; position L: $F_{2,54}=7.31, P=0.002, f=1.07$; position $\mathrm{R}: F_{2,54}=4.35, P=0.018, f=0.39$; position RR: $\left.F_{2,54}=38.35, P<0.001, f=1.15\right)$. Subjects used their left hand more frequently for the QHPFG task than for the QHP-NG task at the two leftward positions (paired $t$ test: position LL: $P$ $<0.001$; position L: $P=0.030$; Fig. 3) whereas they used their right hand more frequently at the more rightward position RR (paired $t$ test: position R: $P=0.100$; position RR: $P<0.001$; Fig. 3). Similarly, subjects used their left hand more frequently for the QHP-P task than for the QHP-NG task at the two leftward positions (paired $t$ test: position LL: $P<0.001$; position L: $P=0.008$; Fig. 3) whereas they used their right hand more frequently at the more rightward position RR (paired $t$ test: position R: $P=0.100$; position RR: $P<0.001$; Fig. 3 ). In contrast, HI values did not differ significantly between the QHP-P and the QHP-FG tasks, regardless of the position (paired $t$ test: position LL: $P=0.930$; position L: $P=0.474$; position R: $P=0.950$; position RR: $P=0.710$; Fig. 3 ).

We then assessed how the position of the food items affected manual laterality according to the task. First, we conducted a mixed ANOVA on HI values as a function of position in each task separately. The analysis revealed a significant main effect of the position 
for the three tasks (ANOVA: QHP-P: $F_{4,108}=39.86, P<0.001, f=1.22$; QHP-FG: $F_{4,108}=$ 19.54, $P<0.001, f=0.85$; QHP-NG: $\left.F_{4,108}=47.10, P<0.001, f=1.33\right)$. Second, we performed Pearson correlation tests to evaluate whether there was a linear variation in the direction of manual laterality according to the location of the items. We found that HI values decreased significantly from the more leftward position LL to the more rightward position RR for both the QHP-P task (Pearson correlation test: $r_{139}=-0.54, P<0.001$; Fig. 3) and the QHP-FG task (Pearson correlation test: $r_{139}=-0.61, P<0.001$; Fig. 3), but increased from position LL to position RR for the QHP-NG task (Pearson correlation test: $r_{139}=0.28, P<$ 0.001; Fig. 3).

$<$ H2>Influence of sex

In adult subjects from both species, we conducted a mixed ANOVA on HI values as a function of sex and task to assess whether manual laterality differed between males and females according to the task. The analysis showed neither a sex effect (ANOVA: $F_{1,20}=$ $3.39, P=0.081, f=0.47$, power $=0.37)$ nor a sex $*$ task interaction $\left(\right.$ ANOVA: $F_{2,40}=0.15, P=$ $0.965, f=0.04$, power $=0.06)$. In both sexes, we found that HI values decreased significantly from the more leftward position LL to the more rightward position RR for both the QHP-P task (Pearson correlation test: males: $r_{34}=-0.62, P<0.001$; females: $r_{69}=-0.50, P<0.001$ ) and the QHP-FG task (Pearson correlation test: males: $r_{34}=-0.59, P<0.001$; females: $r_{69}=-$ $0.62, P<0.001)$. In contrast, HI values increased significantly from position LL to position RR for the QHP-NG task, but this was true of adult females only (Pearson correlation test: males: $r_{34}=0.07, P=0.688$; females: $\left.r_{69}=0.43, P<0.001\right)$. 
Our study had three main findings about manual laterality for pointing gestures in guenons and mangabeys. First, we found a lack of relationship between individual hand preferences for pointing gestures and for grasping actions to items located nearby. Second, homogeneous pointers believed to possess the greatest skills for pointing referentially were more right-handed for pointing gestures than for grasping actions to items located either nearby or far away, at least in mangabeys. Third, we showed that manual laterality for pointing gestures and for grasping actions to items located far away were similarly affected by the position of items: when the items were placed away from the body midline of the subjects, guenons and mangabeys used the hand contralateral to the items.

In guenons and mangabeys, we did not find any group-level right bias for the production of pointing gestures directed towards items located at the body midline in front of the subjects. In contrast to several studies that showed greater right-hand use for pointing gestures than for grasping actions in both human infants (Bonvillian et al. 1997; Cochet \& Vauclair 2010b; Esseily et al. 2010) and chimpanzees (Hopkins et al. 2005), our results indicated no difference in manual laterality between pointing gestures and grasping actions. However, we found no relationship between individual hand preferences for pointing gestures and for grasping actions to items located nearby. This finding parallels those found in human infants (Cochet \& Vauclair 2010b; Esseily et al. 2010; Jacquet et al. 2012) and chimpanzees (Hopkins \& Wesley 2002; Hopkins \& Cantero 2003). There was also no relationship between hand preferences exhibited for pointing gestures and for grasping actions to items located far away, except in the case of rightward items in mangabeys. Although this lack of consistency between hand preferences for pointing gestures and grasping actions may result from small sample sizes, mangabeys' hand preferences for grasping actions requiring full or low arm 
extensions were, by contrast, strongly and positively related when items were located either on the subject's midline or $30^{\circ}$ from the midline.

As in humans and chimpanzees, manual laterality for pointing gestures seems to be relatively distinct from manual laterality for grasping actions in guenons and mangabeys: pointing gestures may rely on different cerebral structures to those involved in noncommunicative actions in monkeys as in humans and nonhuman apes. By contrast, a strong relationship exists between manual laterality for grasping actions requiring either full or low arm extension. Our study thus provides additional evidence that the cognitive processes underlying the production of requesting gestures in monkeys might be distinct from that involved in the execution of grasping actions, even if monkeys had to be trained to produce requesting gestures from a ritualization of reaching movements.

We found that the mangabey individuals possessing the greatest skills for pointing referentially were more right-handed for pointing gestures than for grasping actions (towards items located either nearby or far away). These seven individuals (i.e. homogeneous pointers) were more right-handed than the other nine individuals (i.e. heterogeneous pointers) for the production of pointing gestures whereas these two categories of individuals did not differ in their direction of manual laterality for grasping actions (requiring full or low arm extensions). Thus, we actually found a greater right-hand use for gestures compared to noncommunicative actions when we considered the mangabeys that were the best referential pointers. This predominant right-hand use for pointing gestures may reflect the activation of a specific leftlateralized communicative cerebral system involved in the production of communicative gestures which would be distinct from that involved in the production of purely motor actions. One may note that the probability of detecting a significant group-level right-hand bias in mangabeys for gesturing was fairly low in the present study. No more than 16 mangabeys were available for testing and among them only those that possessed the greatest skills for 
pointing referentially were more right-handed for pointing gestures than for grasping actions. We believe that an increase in sample size should allow the detection of a right-hand preference for the production of pointing gestures in mangabeys. Our findings suggest that the referential nature of the communicative signal may be a necessary condition for the activation of the left-hemispheric communicative system. In future laterality studies, we encourage investigations on interindividual differences in the referential abilities for the production of communicative signals.

Surprisingly, we did not find any increase in right-hand use for pointing gestures compared to grasping actions in guenons, although 10 of the 12 tested subjects exhibited considerable skills for pointing referentially. However, guenons were more right-handed than mangabeys for both pointing gestures and grasping actions. A simple explanation might thus be that the right-sided asymmetry was already too strongly marked in the tested group of guenons to increase it any further for the production of communicative gestures compared to grasping actions. Such an effect was indeed reported in strongly right-handed human adults (Calvert \& Bishop 1998; Cochet \& Vauclair 2012).

Guenons and mangabeys produced pointing gestures using the hand contralateral to the items. Conversely, humans of various ages (infants: Butterworth 2002; Esseily et al. 2010; Jacquet et al. 2012; Meunier et al. 2012; children: Hill \& Khanem 2009; adults: Calvert \& Bishop 1998; Bryden et al. 2000), baboons (Meunier et al. 2012) and chimpanzees (Krause \& Fouts 1997; Hopkins \& Wesley 2002) have been shown to use the ipsilateral hand to the items to make requests.

Additionally, guenons and mangabeys mainly performed grasping actions requiring low arm extensions using the hand ipsilateral to the items. Similarly, humans (infants: Jacquet et al. 2012; children: Bishop et al. 1996; Gabbard 1998, 2001; Carlier et al. 2006, Leconte \& Fagard 2006; adults: Seltzer et al. 1990; Harris \& Carlson 1993; Calvert \& Bishop 1998; 
Bryden et al. 1999; Doyen \& Carlier 2002; Rezaee et al. 2010), macaques (Cronholm et al. 1963; Lehman 1978, 1980a, b), baboons (Meunier et al. 2011) and lemurs (Forsythe et al. 1988) usually grasp using the hand closest to the items, although they more often perform midline crossing with the preferred hand rather than the nonpreferred hand. Surprisingly, guenons and mangabeys performed grasping actions requiring full arm extension using the hand contralateral to the items. Similarly, bushbabies, which are arboreal prosimian primates, have been shown to engage in contralateral grasping when they had to pick up items placed laterally and far away from them (Ward et al. 1993). Altogether, these results stand in contrast to many reports from human studies which show that manual laterality for grasping actions to items located laterally is not affected by an increase in the distance between the individual and the items (e.g. adults: Harris \& Carlson 1993; Stins et al. 2001).

Briefly, manual laterality for pointing gestures and for grasping actions directed towards items located laterally and far away were similarly affected by the position of the items in guenons and mangabeys. One could argue that the opening in the cage mesh was too small to allow subjects to produce movements requiring full arm extensions using the hand ipsilateral to the items located leftward or rightward. However, adult females from both species used the hand contralateral to the objects when they performed pointing gestures and grasping actions requiring full arm extensions to objects placed laterally, despite the fact that they were smaller than the adult males and consequently less constrained by the cage mesh. We propose that the use of the contralateral hand is preferred by guenons and mangabeys for pointing gestures and grasping actions requiring full arm extensions because these two activities are subject to the same biomechanical constraints. Mark et al. (1997) suggested that contralateral movements involving multiple parts of the body may be more comfortable for movements directed towards items placed laterally and far away because none of the limb segments approach complete extension. In addition, differences in habitat may explain the controversial results 
between species: arboreal primates adapted to tree climbing, such as guenons, mangabeys and galagos, may not avoid postural instability in contrast to more terrestrial primates such as humans, chimpanzees and baboons. Arboreal primates would thus perform forward and lateral movements of the upper torso to produce a contralateral reaching whereas terrestrial primates would prefer to extend one shoulder to produce an ipsilateral reaching (humans: Mark et al. 1997; Westwood et al. 2000). Moreover, arboreal primates may use postural adjustments to secure sideway motions. They would hold on with the hand ipsilateral to the item to request/grasp to ensure their safety while leaning laterally, the contralateral hand remaining the only one free. In the present study, we indeed observed that sideway motions of guenons and mangabeys often co-occurred with holding on to the stool or to the cage mesh with the ipsilateral hand to the item. Our finding thus suggests that, when primates have to perform pointing gestures or grasping actions directed towards distant and laterally placed items, arboreal species but not terrestrial species may deal with the biomechanical constraints of these movements by using the contralateral hand to the items.

In conclusion, we showed that hand preferences for pointing gestures and grasping actions that required low arm extensions were not related in guenons and mangabeys. This finding suggests that communicative gestures do not rely on the same cerebral structures as noncommunicative actions in Old World monkeys. Importantly, we also revealed an interaction between referential abilities and hand preferences for pointing gestures in mangabeys: the monkeys possessing the greatest skills for pointing referentially were more right-handed for gesturing than for grasping. We propose that in Old World monkeys, as in chimpanzees, the production of intentional and referential gestures may involve the activation of specific regions of the left hemisphere specialized in the processing of intentional and referential communicative signals. Finally, we found that guenons and mangabeys used the 
hand contralateral to the items for the execution of both pointing gestures and grasping actions requiring full arm extensions. We postulate that the position of the items similarly affects manual laterality for these two types of arm movements because they are subject to the same biomechanical constraints in species adapted to tree climbing.

\section{ACKNOWLEDGMENTS}

We thank Arnaud Rossard for taking care of the monkeys and assisting in every step of the training, Lucie Engelhart for her participation in experiments on Campbell's monkeys and Claire Pettoello for helping in data scoring. We also thank Jacques Vauclair, Jacqueline Fagard, Hélène Meunier, Hélène Cochet, Adrien Meguerditchian, Marie Bourjade and James R. Anderson for helpful discussions about the methodology. We express many thanks to Pascaline Le Gouar, Eric Petit and Maxime Hervé for helpful advice on statistical analyses. We are grateful to two anonymous referees for valuable comments on the manuscript and to Cléo Beaulieu for polishing the English. This study was supported by a French National Research Agency grant: reference ANR-08-BLAN-0.011_01.

\section{REFERENCES}

Anderson, J. R., Kuroshima, H., Hattori, Y. \& Fujita, K. 2010. Flexibility in the use of requesting gestures in squirrel monkeys (Saimiri sciureus). American Journal of Primatology, 72, 707-714. 
Bates, E. \& Dick, F. 2002. Language, gesture, and the developing brain. Developmental Psychobiology, 40, 293-310.

Bishop, D. V., Ross, V. A., Daniels, M. S. \& Bright, P. 1996. The measurement of hand preference: a validation study comparing three groups of right-handers. British Journal of Psychology, 87, 269-285.

Blake, J., O'Rourke, P. \& Borzellino, G. 1994. Form and function in the development of pointing and reaching gestures. Infant Behavior and Development, 17, 195-203.

Bonvillian, J. D., Richards, H. C. \& Dooley, T. T. 1997. Early sign language acquisition and the development of hand preference in young children. Brain and Language, 58, $1-22$.

Bryden, P. J., Pryde, K. M. \& Roy, E. A. 1999. Preferential reaching into hemispace: an examination of performance, preference, and task complexity. Brain and Cognition, 40, 64-67.

Bryden, P. J., Pryde, K. M. \& Roy, E. A. 2000. A performance measure of the degree of hand preference. Brain and Cognition, 44, 402-414.

Butterworth, G. F. 2002. Dynamic aspects of visual event perception and the production of pointing by human infants. British Journal of Developmental Psychology, 20, 1-24.

Call, J. \& Tomasello, M. 2007a. The Gestural Communication of Apes and Monkeys. Mahwah, New Jersey: Psychology Press.

Call, J. \& Tomasello, M. 2007b. Comparing the gestures of apes and monkeys. In: The Gestural Communication of Apes and Monkeys (Ed. by J. Call \& M. Tomasello), pp. 197-220. Mahwah, New Jersey: Psychology Press.

Calvert, G. A. \& Bishop, D. V. M. 1998. Quantifying hand preference using a behavioural continuum. Laterality, 3, 255-268. 
Cantalupo, C. \& Hopkins, W. D. 2010. The cerebellum and its contribution to complex tasks in higher primates: a comparative perspective. Cortex, 46, 821-830.

Carlier, M., Doyen, A.-L. \& Lamard C. 2006. Midline crossing: developmental trend from 3 to 10 years of age in a preferential card-reaching task. Brain and Cognition, 61, 255261.

Chapelain, A., Laurence, A., Vimond, M., Maille, A., Meunier, H., Fagard, J., Vauclair, J. \& Blois-Heulin, C. 2012. Hand preference and its flexibility according to the position of the object: a study in cercopithecines examining spontaneous behaviour and an experimental task (the Bishop QHP task). Animal Cognition, 15, 937-953.

Cochet, H. 2012. Development of hand preference for object-directed actions and pointing gestures: a longitudinal study between 15 and 25 months of age. Developmental Psychobiology, 54, 105-111.

Cochet, H. \& Vauclair, J. 2010a. Features of spontaneous pointing gestures in toddlers. Gesture, 10, 86-107.

Cochet, H. \& Vauclair, J. 2010b. Pointing gestures produced by toddlers from 15 to 30 months: different functions, hand shapes and laterality patterns. Infant Behavior and Development, 33, 431-441.

Cochet, H. \& Vauclair, J. 2012. Hand preferences in human adults: non-communicative actions versus communicative gestures. Cortex, 48, 1017-1026.

Cochet, H., Jover, M. \& Vauclair, J. 2011. Hand preference for pointing gestures and bimanual manipulation around the vocabulary spurt period. Journal of Experimental Child Psychology, 110, 393-407. 
Corina, D. P., Vaid, J. \& Bellugi, U. 1992. The linguistic basis of left hemisphere specialization. Science, 255, 1258-1260.

Corina, D. P., Poizner, H., Bellugi, U., Feinberg, T., Dowd, D. \& O'Grady-Batch, L. 1993. Dissociation between linguistic and nonlinguistic gestural systems: a case for compositionality. Brain and Language, 43, 414-447.

Cronholm, J. N., Grodsky, M. \& Behar, I. 1963. Situational factors in the lateral preference of rhesus monkeys. The Journal of Genetic Psychology, 103, 167-174.

Doyen, A.-L. \& Carlier, M. 2002. Measuring handedness: a validation study of Bishop's reaching card test. Laterality, 7, 115-130.

Esseily, R., Jacquet, A.-Y. \& Fagard, J. 2010. Handedness for grasping objects and pointing and the development of language in 14-month-old infants. Laterality, 16, $565-585$.

Faul, F., Erdfelder, E., Lang, A. G. \& Buchner, A. 2007. G* Power 3: a flexible statistical power analysis program for the social, behavioral, and biomedical sciences. Behavior Research Methods, 39, 175-191.

Forsythe, C., Milliken, G. W., Stafford, D. K. \& Ward, J. P. 1988. Posturally related variations in the hand preferences of the ruffed lemur (Varecia variegata variegata). Journal of Comparative Psychology, 102, 248-250.

Gabbard, C. 1998. Attentional stimuli and programming hand selection: a developmental perspective. International Journal of Neuroscience, 96, 205-215.

Gabbard, C. 2001. Lateralized effects on reaching by children. Developmental Neuropsychology, 19, 41-51.

Gautier-Hion, A., Colyn, M. \& Gautier, J.-P. 1999. Histoire Naturelle des Primates d'Afrique Centrale. Libreville: Multipress Gabon Libreville. 
Gómez, J.-C. 2005. Requesting gestures in captive monkeys and apes: conditioned responses or referential behaviours? Gesture, 5, 91-105.

Harris, L. J. \& Carlson, D. F. 1993. Hand preference for visually-guided reaching in human infants and adults. In: Primate Laterality: Current Behavioral Evidence of Primate Asymmetries (Ed. by J. P. Ward \& W. D. Hopkins), pp. 285-305. New York: Springer-Verlag.

Hattori, Y., Kuroshima, H. \& Fujita, K. 2010. Tufted capuchin monkeys (Cebus apella) show understanding of human attentional states when requesting food held by a human. Animal Cognition, 13, 87-92.

Hickok, G., Bellugi, U. \& Klima, E., S. 1998. The neural organization of language: evidence from sign language aphasia. Trends in Cognitive Sciences, 2, 129-136.

Hill, E. L. \& Khanem, F. 2009. The development of hand preference in children: the effect of task demands and links with manual dexterity. Brain and Cognition, 71, 99-107.

Hopkins, W. D. \& Cantalupo, C. 2004. Handedness in chimpanzees (Pan troglodytes) is associated with asymmetries of the primary motor cortex but not with homologous language areas. Behavioral Neuroscience, 118, 1176-1183.

Hopkins, W. D. \& Cantero, M. 2003. From hand to mouth in the evolution of language: the influence of vocal behavior on lateralized hand use in manual gestures by chimpanzees (Pan troglodytes). Developmental Science, 6, 55-61.

Hopkins, W. D. \& Leavens, D. A. 1998. Hand use and gestural communication in chimpanzees (Pan troglodytes). Journal of Comparative Psychology, 112, 95-99.

Hopkins, W. D. \& Nir, T. M. 2010. Planum temporale surface area and grey matter asymmetries in chimpanzees (Pan troglodytes): the effect of handedness and comparison with findings in humans. Behavioural Brain Research, 208, 436-443. 
Hopkins, W. D. \& de Waal, F. 1995. Behavioral laterality in captive bonobos (Pan paniscus): replication and extension. International Journal of Primatology, 16, 261276.

Hopkins, W. D. \& Wesley, M. J. 2002. Gestural communication in chimpanzees (Pan troglodytes): the influence of experimenter position on gesture type and hand preference. Laterality, 7, 19-30.

Hopkins, W. D., Russell, J., Freeman, H., Buehler, N., Reynolds, E. \& Schapiro, S. J. 2005. The distribution and development of handedness for manual gestures in captive chimpanzees (Pan troglodytes). Psychological Science, 16, 487-493.

Hopkins, W. D., Pika, S., Liebal, K., Bania, A., Meguerditchian, A., Gardner, M. \& Schapiro, S. 2012. Handedness for manual gestures in great apes: a meta-analysis. In: Developments in Primate Gesture Research (Ed. by S. Pika \& K. Liebal), pp. 93-110. Amsterdam: John Benjamins.

Horwitz, B., Amunts, K., Bhattacharyya, R., Patkin, D., Jeffries, K., Zilles, K. \& Braun, A. R. 2003. Activation of Broca's area during the production of spoken and signed language: a combined cytoarchitectonic mapping and PET analysis. Neuropsychologia, 41, 1868-1876.

Jacquet, A., Esseily, R., Rider, D. \& Fagard, J. 2012. Handedness for grasping objects and declarative pointing: a longitudinal study. Developmental Psychobiology, 54, 34-46.

Jolly, A. 1964. Choice of cue in Prosimian learning. Animal Behaviour, 12, 571-577.

Kimura, D. 1973a. Manual activity during speaking: I. Right-handers. Neuropsychologia, 11, 45-50.

Kimura, D. 1973b. Manual activity during speaking: II. Left-handers. Neuropsychologia, 11, 51-55. 
Krause, M. A. \& Fouts, R. S. 1997. Chimpanzee (Pan troglodytes) pointing: hand shapes, accuracy, and the role of eye gaze. Journal of Comparative Psychology, 111, 330-336.

Leavens, D. A. 2004. Manual deixis in apes and humans. Interaction Studies, 5, 387-408.

Leconte, P. \& Fagard, J. 2006. Which factors affect hand selection in children's grasping in hemispace? Combined effects of task demand and motor dominance. Brain and Cognition, 60, 88-93.

Lehman, R. A. W. 1978. The handedness of rhesus monkeys: I. Distribution. Neuropsychologia, 16, 33-42.

Lehman, R. A. W. 1980a. Distribution and changes in strength of hand preference of Cynomolgus monkeys. Brain, Behavior and Evolution, 17, 209-217.

Lehman, R. A. W. 1980b. Persistence of primate hand preference despite initial training to the contrary. Behavioural Brain Research, 1, 547-551.

MacNeilage, P. F. 1993. Implications of primate functional asymmetries for the evolution of cerebral hemispheric specializations. In: Primate Laterality: Current Behavioral Evidence of Primate Asymmetries (Ed. by J.P. Ward \& W. D. Hopkins), pp. 319-341. New York: Springer-Verlag.

MacNeilage, P. F. 2007. Present status of the postural origins theory. In: The Evolution of Hemispheric Specialization in Primates (Ed. by W. D. Hopkins), pp. 59-91. London: Academic Press.

Maille, A., Engelhart, L., Bourjade, M. \& Blois-Heulin, C. 2012. To beg, or not to beg? That is the question: mangabeys modify their production of requesting gestures in response to human's attentional states. PLoS ONE, 7, e41197.

Mark, L. S., Nemeth, K., Gardner, D., Dainoff, M. J., Paasche, J., Duffy, M. \& Grandt, K. 1997. Postural dynamics and the preferred critical boundary for visually guided reaching. Journal of Experimental Psychology, 23, 1365-1379. 
Meguerditchian, A. \& Vauclair, J. 2006. Baboons communicate with their right hand. Behavioural Brain Research, 171, 170-174.

Meguerditchian, A. \& Vauclair, J. 2009. Contrast of hand preferences between communicative gestures and non-communicative actions in baboons: implications for the origins of hemispheric specialization for language. Brain \& Language, 108, 167174.

Meguerditchian, A., Vauclair, J. \& Hopkins, W. D. 2010. Captive chimpanzees use their right hand to communicate with each other: implications for the origin of the cerebral substrate for language. Cortex, 46, 40-48.

Meguerditchian, A., Molesti, S. \& Vauclair, J. 2011. Right-handedness predominance in 162 baboons (Papio anubis) for gestural communication: consistency across time and groups. Behavioral Neuroscience, 125, 653-660.

Meguerditchian, A., Gardner, M. J., Schapiro, S. J. \& Hopkins, W. D. 2012. The sound of one-hand clapping: handedness and perisylvian neural correlates of a communicative gesture in chimpanzees. Proceedings of the Royal Society B, 279, 1959-1966.

Meunier, H., Blois-Heulin, C. \& Vauclair, J. 2011. A new tool for measuring hand preference in non-human primates: adaptation of Bishop's Quantifying Hand Preference task for olive baboons. Behavioural Brain Research, 218, 1-7.

Meunier, H., Vauclair, J. \& Fagard, J. 2012. Human infants and baboons show the same pattern of handedness for a communicative gesture. PLoS ONE, 7, e33959.

Meunier, H., Prieur, J. \& Vauclair, J. 2013. Olive baboons communicate intentionally by pointing. Animal Cognition, 16, 155-163.

Oates, J. F. 1988. The distribution of Cercopithecus monkeys in West Afican forests. In: A Primate Radiation: Evolutionary Biology of the African Guenons (Ed. by A Gautier- 
Hion, F. Bourlière, J.-P. Gautier \& J. Kingdon), pp. 79-103. Cambridge: Cambridge University Press.

Rezaee, M., Shojaee, M., Ghasemi, A., Moghaddam, A. \& Momeni, M. 2010. Which factors affect hand selection in adults? Combined effects of ocular dominance, task demand and object location. Journal of Human Kinetics, 26, 39-44.

Rogers, L. J. \& Kaplan, G. 1996. Hand preferences and other lateral biases in rehabilitated orang-utans, Pongo pygameus pygmaeus. Animal Behaviour, 51, 13-25.

Seltzer, C., Forsythe, C. \& Ward, J. P. 1990. Multiple measures of motor lateralization in human primates (Homo sapiens). Journal of Comparative Psychology, 104, 159-166.

Shafer, D. 1997. Hand preference behaviors shared by two groups of captive bonobos. Primates, 38, 303-313.

Skipper, J. I., Goldin-Meadow, S., Nusbaum, H. C. \& Small, S. L. 2007. Speechassociated gestures, Broca's area, and the human mirror system. Brain and Language, 101, 260-277.

Stins, J. F., Kadar, E. E. \& Costall, A. 2001. A kinematic analysis of hand selection in a reaching task. Laterality, $\mathbf{6}, 347$.

Taglialatela, J. P., Cantalupo, C. \& Hopkins, W. D. 2006. Gesture handedness predicts asymmetry in the chimpanzee inferior frontal gyrus. Neuroreport, 17, 923-927.

Taglialatela, J. P., Russell, J. L., Schaeffer, J. A. \& Hopkins, W. D. 2008. Communicative signaling activates 'Broca's' homolog in chimpanzees. Current Biology, 18, 343-348.

Taglialatela, J. P., Russell, J. L., Schaeffer, J. A. \& Hopkins, W. D. 2011. Chimpanzee vocal signaling points to a multimodal origin of human language. PLoS ONE, 6, e18852. 
Vauclair, J. \& Imbault, J. 2009. Relationship between manual preferences for object manipulation and pointing gestures in infants and toddlers. Developmental Science, 12, 1060-1069.

Ward, J. P., Milliken, G. \& Stafford, D. 1993. Patterns of lateralized behavior in Prosimians. In: Primate Laterality: Current Behavioral Evidence of Primate Asymmetries (Ed. by J. P. Ward \& W. D. Hopkins), pp. 43-74. New York: SpringerVerlag.

Westwood, D. A., Roy, E. A. \& Bryden, P. J. 2000. Posture and target location effects on manual preference. Brain and Cognition, 43, 421-425.

Xu, J., Gannon, P. J., Emmorey, K., Smith, J. F. \& Braun, A. R. 2009. Symbolic gestures and spoken language are processed by a common neural system. Proceedings of the National Academy of Sciences, U.S.A., 106, 20664-20669. 
Table 1. Individual characteristics of each subject

\begin{tabular}{|c|c|c|c|c|c|c|c|c|c|c|c|}
\hline \multirow[b]{2}{*}{ Subject } & \multicolumn{11}{|c|}{ QHP-Pointing task } \\
\hline & Sex & Age & Class & LL & $\mathrm{L}$ & $\mathrm{C}$ & $\mathrm{R}$ & RR & $\chi^{2}$ & $P$ & $\begin{array}{c}\text { Pointer } \\
\text { category }\end{array}$ \\
\hline \multicolumn{12}{|l|}{ Guenons } \\
\hline Ecureuil & Female & 4.5 & Adult & 70 & 58 & 50 & 67 & 55 & 4.63 & 0.327 & Hom. \\
\hline Chili & Female & 5.5 & Adult & 62 & 59 & 55 & 59 & 65 & 0.93 & 0.920 & Hom. \\
\hline Amande & Female & 6.5 & Adult & 67 & 55 & 63 & 67 & 48 & 4.60 & 0.331 & Hom. \\
\hline Chilula & Female & 15.0 & Adult & 63 & 65 & 55 & 53 & 63 & 1.95 & 0.744 & Hom. \\
\hline Tilamook & Female & 15.0 & Adult & 65 & 62 & 52 & 35 & 83 & 20.96 & $<0.001$ & Het. \\
\hline Maricopa & Female & 16.0 & Adult & 56 & 55 & 74 & 53 & 62 & 4.83 & 0.305 & Hom. \\
\hline Lowina & Female & 17.5 & Adult & 72 & 65 & 50 & 59 & 53 & 5.33 & 0.255 & Hom. \\
\hline Shawnee & Female & 17.5 & Adult & 59 & 66 & 47 & 77 & 50 & 9.95 & 0.041 & Het. \\
\hline Plume & Female & 18.5 & Adult & 58 & 70 & 61 & 57 & 53 & 2.72 & 0.605 & Hom. \\
\hline Lombrik & Male & 4.0 & Adult & 53 & 70 & 72 & 52 & 53 & 6.77 & 0.149 & Hom. \\
\hline Lowi & Male & 5.5 & Adult & 50 & 58 & 74 & 66 & 52 & 6.67 & 0.155 & Hom. \\
\hline Arbok & Male & 8.5 & Adult & 59 & 50 & 79 & 59 & 52 & 8.81 & 0.066 & Hom. \\
\hline \multicolumn{12}{|c|}{ Mangabeys } \\
\hline Lorette & Female & 2.0 & Juvenile & 64 & 55 & 57 & 51 & 71 & 4.22 & 0.378 & Hom. \\
\hline Many & Female & 2.0 & Juvenile & 74 & 57 & 52 & 44 & 73 & 11.57 & 0.021 & Het. \\
\hline Chipse & Female & 4.5 & Juvenile & 60 & 53 & 82 & 57 & 48 & 11.43 & 0.022 & Het. \\
\hline Julie & Female & 6.0 & Adult & 62 & 57 & 69 & 51 & 61 & 2.93 & 0.569 & Hom. \\
\hline Bell & Female & 8.5 & Adult & 55 & 51 & 75 & 40 & 61 & 10.29 & 0.036 & Het. \\
\hline Goffrette & Female & 13.5 & Adult & 48 & 46 & 59 & 71 & 76 & 11.97 & 0.018 & Het. \\
\hline Chipie & Female & 18.0 & Adult & 61 & 87 & 62 & 45 & 43 & 20.93 & $<0.001$ & Het. \\
\hline Zunie & Female & 23.0 & Adult & 27 & 113 & 95 & 34 & 24 & 120.91 & $<0.001$ & Het. \\
\hline Carillon & Male & 3.5 & Juvenile & 90 & 22 & 54 & 59 & 75 & 43.43 & $<0.001$ & Het. \\
\hline Lenni & Male & 3.5 & Juvenile & 53 & 72 & 63 & 53 & 59 & 4.20 & 0.380 & Hom. \\
\hline George & Male & 4.0 & Juvenile & 68 & 59 & 62 & 68 & 43 & 7.03 & 0.134 & Hom. \\
\hline
\end{tabular}




$\begin{array}{lllllllllrlr}\text { Isba } & \text { Male } & 6.5 & \text { Juvenile } & 58 & 60 & 70 & 66 & 46 & 5.60 & 0.231 & \text { Hom. } \\ \text { Marti } & \text { Male } & 11.5 & \text { Adult } & 55 & 54 & 73 & 69 & 49 & 7.20 & 0.126 & \text { Hom. } \\ \text { Filou } & \text { Male } & 17.0 & \text { Adult } & 79 & 53 & 71 & 48 & 48 & 13.69 & 0.008 & \text { Het. } \\ \text { Pirate } & \text { Male } & 17.5 & \text { Adult } & 71 & 57 & 70 & 52 & 49 & 6.94 & 0.139 & \text { Hom. } \\ \text { Rapide } & \text { Male } & 22.0 & \text { Adult } & 117 & 57 & 28 & 24 & 73 & 96.10 & <0.001 & \text { Het. }\end{array}$

Age $=$ age in years; class $=$ age class $; \mathrm{LL}=$ number of pointing gestures directed towards the position $\mathrm{LL}\left(-60^{\circ}\right) ; \mathrm{L}=$ number of pointing gestures directed towards the position $\mathrm{L}\left(-30^{\circ}\right) ; \mathrm{C}=$ number of pointing gestures directed towards the position $\mathrm{C}\left(0^{\circ}\right)$; $\mathrm{R}=$ number of pointing gestures directed towards the position $\mathrm{R}\left(+30^{\circ}\right)$; $\mathrm{RR}=$ number of pointing gestures directed towards the position $\mathrm{RR}\left(+60^{\circ}\right) ; \chi^{2}=$ chi-square random variable from the chi-square test; $P=$ probability from the chi-square test; pointer category = pointer category based on the chi-square test $($ Hom. $=$ homogeneous pointer; Het. $=$ heterogeneous pointer) . 
Table 2. Raw data and individual handedness index (HI) for pointing gestures (QHP-Pointing task) and grasping actions (QHP-Far Grasping task and QHP-Nearby Grasping task) directed towards the central position

\begin{tabular}{|c|c|c|c|c|c|c|c|c|c|c|c|c|c|c|c|}
\hline \multirow[b]{2}{*}{ Subject } & \multicolumn{5}{|c|}{ QHP-Pointing task } & \multicolumn{5}{|c|}{ QHP-Far Grasping task } & \multicolumn{5}{|c|}{ QHP-Nearby Grasping task } \\
\hline & Left & Right & $P$ & Bias & $\mathrm{HI}$ & Left & Right & $P$ & Bias & $\mathrm{HI}$ & Left & Right & $P$ & Bias & HI \\
\hline \multicolumn{16}{|l|}{ Guenons } \\
\hline Ecureuil & 13 & 31 & 0.010 & $\mathrm{R}$ & 0.41 & 49 & 11 & $<0.001$ & $\mathrm{~L}$ & -0.63 & 35 & 25 & 0.245 & A & -0.17 \\
\hline Chili & 55 & 0 & $<0.001$ & $\mathrm{~L}$ & -1.00 & 10 & 50 & $<0.001$ & $\mathrm{R}$ & 0.67 & 3 & 57 & $<0.001$ & $\mathrm{R}$ & 0.90 \\
\hline Amande & 3 & 43 & $<0.001$ & $\mathrm{R}$ & 0.87 & 44 & 16 & $<0.001$ & $\mathrm{~L}$ & -0.47 & 11 & 49 & $<0.001$ & $\mathrm{R}$ & 0.63 \\
\hline Chilula & 22 & 30 & 0.332 & A & 0.15 & 21 & 39 & 0.027 & $\mathrm{R}$ & & 45 & 15 & $<0.001$ & $\mathrm{~L}$ & -0.50 \\
\hline Tilamook & 11 & 38 & $<0.001$ & $\mathrm{R}$ & 0.55 & 10 & 50 & $<0.001$ & $\mathrm{R}$ & 0.67 & 11 & 49 & $<0.001$ & $\mathrm{R}$ & 0.63 \\
\hline Maricopa & 0 & 74 & $<0.001$ & $\mathrm{R}$ & 1.00 & 14 & 46 & $<0.001$ & $\mathrm{R}$ & 0.53 & 25 & 35 & 0.245 & A & 0.17 \\
\hline Lowina & 1 & 46 & $<0.001$ & $\mathrm{R}$ & 0.96 & 12 & 48 & $<0.001$ & $\mathrm{R}$ & 0.60 & 10 & 50 & $<0.001$ & $\mathrm{R}$ & 0.67 \\
\hline Shawnee & 0 & 50 & $<0.001$ & $\mathrm{R}$ & 1.00 & 7 & 53 & $<0.001$ & $\mathrm{R}$ & 0.7 & 30 & 30 & 1.000 & A & 0.00 \\
\hline Plume & 58 & 3 & $<0.00$ & $\mathrm{~L}$ & -0.90 & 24 & 36 & 0.155 & A & 0.2 & 21 & 39 & 0.027 & $\mathrm{R}$ & 0.30 \\
\hline Lombrik & 59 & 13 & $<0.001$ & $\mathrm{~L}$ & -0.64 & 35 & 25 & 0.245 & A & -0.17 & 41 & 19 & 0.006 & $\mathrm{~L}$ & -0.37 \\
\hline Lowi & 12 & 50 & $<0.001$ & $\mathrm{R}$ & 0.61 & 35 & 25 & 0.245 & A & -0.17 & 34 & 26 & 0.366 & A & -0.13 \\
\hline Arbok & 0 & 78 & $<0.001$ & $\mathrm{R}$ & 1.00 & 0 & 60 & $<0.001$ & $\mathrm{R}$ & 1.00 & 20 & 40 & 0.013 & $\mathrm{R}$ & 0.33 \\
\hline \multicolumn{16}{|l|}{ Mangabeys } \\
\hline Lorette & 24 & 33 & 0.289 & A & 0.16 & 16 & 44 & $<0.001$ & $\mathrm{R}$ & 0.47 & 23 & 37 & 0.092 & A & 0.23 \\
\hline Many & 45 & 0 & $<0.001$ & $\mathrm{~L}$ & -1.00 & 18 & 42 & 0.003 & $\mathrm{R}$ & 0.40 & 2 & 58 & $<0.001$ & $\mathrm{R}$ & 0.93 \\
\hline Chipse & 7 & 10 & 0.629 & A & 0.18 & 26 & 33 & 0.435 & A & 0.12 & 42 & 18 & 0.003 & $\mathrm{~L}$ & -0.40 \\
\hline Julie & 2 & 67 & $<0.001$ & $\mathrm{R}$ & 0.94 & 20 & 40 & 0.013 & $\mathrm{R}$ & & 51 & 9 & $<0.001$ & $\mathrm{~L}$ & -0.70 \\
\hline Bell & 21 & 11 & 0.110 & A & -0.31 & 31 & 29 & 0.897 & A & -0.03 & 30 & 30 & 1.000 & A & 0.00 \\
\hline Goffrette & 54 & 5 & $<0.001$ & $\mathrm{~L}$ & -0.83 & 60 & 0 & $<0.001$ & $\mathrm{~L}$ & -1.00 & 52 & 8 & $<0.001$ & $\mathrm{~L}$ & -0.73 \\
\hline Chipie & 62 & 0 & $<0.001$ & $\mathrm{~L}$ & -1.00 & 45 & 15 & $<0.001$ & $\mathrm{~L}$ & -0.50 & 45 & 15 & $<0.001$ & $\mathrm{~L}$ & -0.50 \\
\hline Zunie & 3 & 91 & $<0.001$ & $\mathrm{R}$ & 0.94 & 10 & 50 & $<0.001$ & $\mathrm{R}$ & 0.67 & 16 & 44 & $<0.001$ & $\mathrm{R}$ & 0.47 \\
\hline
\end{tabular}




$\begin{array}{lccrrrrrrrrrrrrr}\text { Carillon } & 10 & 8 & 0.815 & \mathrm{~A} & -0.11 & 34 & 26 & 0.366 & \mathrm{~A} & -0.13 & 14 & 46 & <0.001 & \mathrm{R} & 0.53 \\ \text { Lenni } & 3 & 60 & <0.001 & \mathrm{R} & 0.90 & 1 & 59 & <0.001 & \mathrm{R} & 0.97 & 31 & 29 & 0.897 & \mathrm{~A} & -0.03 \\ \text { George } & 2 & 28 & <0.001 & \mathrm{R} & 0.87 & 58 & 1 & <0.001 & \mathrm{~L} & -0.97 & 60 & 0 & <0.001 & \mathrm{~L} & -1.00 \\ \text { Isba } & 1 & 36 & <0.001 & \mathrm{R} & 0.95 & 54 & 8 & <0.001 & \mathrm{~L} & -0.74 & 34 & 26 & 0.366 & \mathrm{~A} & -0.13 \\ \text { Marti } & 73 & 0 & <0.001 & \mathrm{~L} & -1.00 & 57 & 1 & <0.001 & \mathrm{~L} & -0.97 & 59 & 1 & <0.001 & \mathrm{~L} & -0.97 \\ \text { Filou } & 71 & 0 & <0.001 & \mathrm{~L} & -1.00 & 40 & 20 & 0.013 & \mathrm{~L} & -0.33 & 1 & 59 & <0.001 & \mathrm{R} & 0.97 \\ \text { Pirate } & 53 & 13 & <0.001 & \mathrm{~L} & -0.61 & 48 & 12 & <0.001 & \mathrm{~L} & -0.60 & 60 & 0 & <0.001 & \mathrm{~L} & -1.00 \\ \text { Rapide } & 28 & 0 & <0.001 & \mathrm{~L} & -1.00 & 60 & 0 & <0.001 & \mathrm{~L} & -1.00 & 60 & 0 & <0.001 & \mathrm{~L} & -1.00\end{array}$

Left $=$ number of trials performed with the left hand; right $=$ number of trials performed with the right hand; $P=$ probability from the binomial test comparing the number of trials performed with the left or the right hand; bias $=$ hand preference based on the binomial test $(\mathrm{A}=$ ambiguously handed; L = left-handed; $\mathrm{R}$ = right-handed). 
Table 3. Consistency in manual laterality between the QHP-Pointing task (QHP-P), the QHP-Far Grasping task (QHP-FG) and the QHP-Nearby Grasping task (QHP-NG)

\begin{tabular}{lccccccccc} 
& \multicolumn{3}{c}{ QHP-P vs QHP-FG } & \multicolumn{3}{c}{ QHP-P vs QHP-NG } & \multicolumn{3}{c}{ QHP-FG vs QHP-NG } \\
Position & $r$ & $P$ & Power & $r$ & $P$ & Power & $r$ & $P$ & Power \\
\hline Guenons $(N=12)$ & & & & & & & & & \\
LL $\left(-60^{\circ}\right)$ & -0.25 & 0.439 & 0.11 & -0.49 & 0.156 & 0.35 & 0.76 & $\mathbf{0 . 0 1 1}$ & 0.85 \\
L $\left(-30^{\circ}\right)$ & 0.05 & 0.872 & 0.04 & -0.29 & 0.546 & 0.13 & 0.57 & 0.155 & 0.49 \\
C $\left(0^{\circ}\right)$ & 0.15 & 0.958 & 0.06 & 0.02 & 0.962 & 0.04 & 0.42 & 0.517 & 0.26 \\
R $\left(+30^{\circ}\right)$ & 0.61 & 0.098 & 0.56 & 0.04 & 0.894 & 0.04 & 0.55 & 0.098 & 0.45 \\
RR $\left(+60^{\circ}\right)$ & 0.36 & 0.529 & 0.19 & 0.20 & 0.529 & 0.08 & 0.27 & 0.529 & 0.12 \\
Mangabeys $(N=16)$ & & & & & & & & & \\
LL $\left(-60^{\circ}\right)$ & 0.43 & 0.144 & 0.38 & 0.02 & 0.936 & 0.04 & 0.49 & 0.144 & 0.49 \\
L $\left(-30^{\circ}\right)$ & 0.45 & 0.116 & 0.41 & 0.02 & 0.953 & 0.04 & 0.64 & $\mathbf{0 . 0 2 3}$ & 0.78 \\
C $\left(0^{\circ}\right)$ & 0.44 & 0.128 & 0.39 & 0.10 & 0.707 & 0.06 & 0.60 & $\mathbf{0 . 0 4 0}$ & 0.71 \\
R $\left(+30^{\circ}\right)$ & 0.54 & $\mathbf{0 . 0 4 7}$ & 0.59 & 0.30 & 0.258 & 0.19 & 0.58 & $\mathbf{0 . 0 4 7}$ & 0.67 \\
RR $\left(+60^{\circ}\right)$ & 0.78 & $\mathbf{0 . 0 1 3}$ & 0.97 & 0.37 & 0.160 & 0.28 & 0.48 & 0.086 & 0.47
\end{tabular}

Position = location (angle from the subject's midline) of either the opaque tube to which the subject pointed (QHP-P) or the food item it grasped (QHP-FG and QHP-NG); $r=$ coefficient of correlation for the Pearson correlation test performed on HI values; $P=$ FDR-adjusted probability from the Pearson correlation test $(F D R=$ false discovery rate $)$ : power $=$ post hoc statistical power. Significant results are shown in bold . 
Table A1. Raw data and individual handedness index (HI) for pointing gestures (QHP-Pointing) directed towards items placed at lateral positions

\begin{tabular}{|c|c|c|c|c|c|c|c|c|c|c|c|c|c|c|c|c|c|c|c|c|}
\hline \multirow[b]{2}{*}{ Subject } & \multicolumn{3}{|c|}{ Position LL $\left(-60^{\circ}\right)$} & \multirow[b]{2}{*}{ Bias } & \multirow[b]{2}{*}{ HI } & \multicolumn{3}{|c|}{ Position L $\left(-30^{\circ}\right)$} & \multirow[b]{2}{*}{ Bias } & \multirow[b]{2}{*}{$\mathrm{HI}$} & \multicolumn{3}{|c|}{ Position R $\left(+30^{\circ}\right)$} & \multirow[b]{2}{*}{ Bias } & \multirow[b]{2}{*}{ HI } & \multicolumn{3}{|c|}{ Position RR $\left(+60^{\circ}\right)$} & \multirow[b]{2}{*}{ Bias } & \multirow[b]{2}{*}{ HI } \\
\hline & Left & Right & $P$ & & & Left & Rioht & $P$ & & & & & $P$ & & & Left & & $P$ & & \\
\hline \multicolumn{21}{|l|}{ Guenons } \\
\hline Ecureuil & 0 & 70 & $<0.001$ & $\mathrm{R}$ & 1.00 & 2 & 53 & $<0.001$ & $\mathrm{R}$ & 0.93 & 49 & 15 & $<0.001$ & $\mathrm{~L}$ & -0.53 & 54 & 1 & $<0.001$ & $\mathrm{~L}$ & -0.96 \\
\hline Chili & 62 & 0 & $<0.001$ & $\mathrm{~L}$ & -1.00 & 58 & 1 & $<0.001$ & $\mathrm{~L}$ & -0.97 & 59 & 0 & $<0.001$ & $\mathrm{~L}$ & -1.00 & 65 & 0 & $<0.001$ & $\overline{\mathrm{R}}$ & -1.00 \\
\hline Amande & 1 & 66 & $<0.001$ & $\mathrm{R}$ & 0.97 & 2 & 54 & $<0.001$ & $\mathrm{R}$ & 0.93 & 62 & 3 & $<0.001$ & $\mathrm{~L}$ & -0.91 & 50 & 0 & $<0.001$ & $\mathrm{R}$ & -1.00 \\
\hline Chilula & 0 & 63 & $<0.001$ & $\mathrm{R}$ & 1.00 & 5 & 59 & $<0.001$ & $\mathrm{R}$ & 0.84 & 45 & 7 & $<0.001$ & $\mathrm{~L}$ & -0.73 & 63 & 0 & $<0.001$ & A & -1.00 \\
\hline Tilamook & 0 & 65 & $<0.001$ & $\mathrm{R}$ & 1.00 & 1 & 61 & $<0.001$ & $\mathrm{R}$ & 0.97 & 30 & 5 & $<0.001$ & $\mathrm{~L}$ & -0.71 & 82 & 1 & 0.001 & $\mathrm{R}$ & -0.98 \\
\hline Maricopa & 0 & 56 & $<0.001$ & $\mathrm{R}$ & 1.00 & 0 & 55 & $<0.001$ & $\mathrm{R}$ & 1.00 & 0 & 53 & $<0.001$ & $\mathrm{R}$ & 1.00 & 0 & 62 & $<0.001$ & $\mathrm{R}$ & 1.00 \\
\hline Shawne & 0 & 59 & $<0.001$ & $\mathrm{R}$ & 1.00 & 0 & 66 & $<0.001$ & $\mathrm{R}$ & 1.00 & 3 & 74 & $<0.001$ & $\mathrm{R}$ & 0.9 & 19 & 31 & 0.119 & $\mathrm{R}$ & 0.24 \\
\hline Low & 0 & 72 & $<0.001$ & $\mathrm{R}$ & 1.00 & 0 & 65 & $<0.001$ & $\mathrm{R}$ & 1.00 & 3 & 56 & $<0.001$ & $\mathrm{R}$ & 0.9 & 39 & 14 & $<0.0$ & A & -0.47 \\
\hline Plum & 3 & 55 & $<0.001$ & $\mathrm{R}$ & 0.90 & 69 & 1 & $<0.001$ & $\mathrm{~L}$ & -0.97 & 49 & 8 & $<0.001$ & $\mathrm{~L}$ & -0.72 & 46 & 7 & $<0.001$ & $\mathrm{R}$ & -0.74 \\
\hline Lom & 0 & 53 & $<0.001$ & $\mathrm{R}$ & 1.00 & 16 & 53 & $<0.0$ & $\mathrm{R}$ & 0.54 & 47 & 4 & $<0.001$ & $\mathrm{~L}$ & -0.8 & 53 & 0 & $<0.001$ & $\mathrm{~L}$ & -1.00 \\
\hline Low & 1 & 49 & $<0.001$ & $\mathrm{R}$ & 0.9 & 4 & 49 & & $\mathrm{R}$ & 0.85 & 51 & 15 & $<0.001$ & $\mathrm{~L}$ & -0 . & 52 & 0 & & $\mathrm{R}$ & -1.00 \\
\hline Arbok & 0 & 59 & $<0.001$ & $\mathrm{R}$ & 1.00 & 0 & 50 & & $\mathrm{R}$ & 1.00 & 2 & & $<0.001$ & $\mathrm{R}$ & 0.93 & 49 & 3 & & $\mathrm{R}$ & -0.88 \\
\hline \multicolumn{21}{|l|}{ Mangabeys } \\
\hline Lorette & 7 & 57 & $<0.001$ & $\mathrm{R}$ & 0.78 & 9 & 46 & & $\mathrm{R}$ & 0.67 & 30 & 19 & 0.152 & A & -0.22 & 48 & 19 & & $\mathrm{~L}$ & -0.43 \\
\hline Man & 51 & 8 & $<0.001$ & $\mathrm{~L}$ & -0.73 & 29 & 0 & & $\mathrm{~L}$ & -1.00 & 36 & 0 & $<0.0$ & $\mathrm{~L}$ & -1.00 & 70 & 1 & & $\mathrm{~L}$ & -0.97 \\
\hline Chip & 1 & 48 & $<0.001$ & $\bar{R}$ & 0.96 & 3 & 16 & $<0.0$ & $\bar{R}$ & 0.68 & 9 & 7 & 0.804 & $\bar{A}$ & -0.1 & 45 & 0 & $<0.001$ & $\overline{\mathrm{L}}$ & -1.00 \\
\hline Julie & 0 & 62 & $<0.001$ & $\mathrm{R}$ & 1.00 & 0 & 57 & $<0.0$ & $\mathrm{R}$ & 1.00 & 3 & 48 & $<0.001$ & $\mathrm{R}$ & 0.8 & 30 & 31 & 1.000 & A & 0.02 \\
\hline Bell & 2 & 53 & $<0.001$ & $\mathrm{R}$ & 0.93 & 3 & 37 & $<0.0$ & $\mathrm{R}$ & 0.85 & 37 & 1 & $<0.001$ & $\mathrm{~L}$ & -0.95 & 61 & 0 & $<0.001$ & $\mathrm{~L}$ & -1.00 \\
\hline Goffrette & 20 & 27 & 0.382 & A & 0.15 & 29 & 17 & 0.104 & A & -0.26 & 69 & 2 & $<0.001$ & $\mathrm{~L}$ & -0.94 & 76 & 0 & $<0.001$ & $\mathrm{~L}$ & -1.00 \\
\hline & 57 & 4 & $<0.001$ & $\mathrm{~L}$ & -0.87 & 87 & 0 & $<0.001$ & $\mathrm{~L}$ & -1.00 & 45 & 0 & $<0.001$ & $\mathrm{~L}$ & -1.0 & 43 & 0 & $<0.001$ & $\mathrm{~L}$ & -1.00 \\
\hline Zun & 0 & 27 & $<0.001$ & $\mathrm{R}$ & 1.0 & 1 & 111 & $<0.001$ & $\mathrm{R}$ & 0.98 & 1 & 32 & $<0.001$ & $\mathrm{R}$ & 0.9 & 13 & 11 & 0.839 & A & -0.08 \\
\hline Carillon & 0 & 90 & $<0.001$ & $\mathrm{R}$ & 1.00 & 4 & 10 & 0.180 & A & 0.43 & 16 & 8 & 0.152 & A & -0.33 & 49 & 7 & $<0.001$ & $\mathrm{~L}$ & -0.75 \\
\hline & 0 & 53 & & $\mathrm{R}$ & 1.0 & 0 & 72 & & $\mathrm{R}$ & 1.00 & 6 & 47 & $<0.001$ & $\mathrm{R}$ & 0.77 & 23 & 36 & & A & 0.22 \\
\hline & 0 & 65 & $<0.001$ & $\mathrm{R}$ & & 3 & 31 & $<0.0$ & $\mathrm{R}$ & 0.82 & 16 & 20 & & A & 0 . & 29 & 7 & $<0.001$ & $\mathrm{~L}$ & -0.61 \\
\hline Isba & 1 & 56 & $<0.001$ & $\mathrm{R}$ & 0.96 & 2 & 29 & $<0.001$ & $\mathrm{R}$ & 0.87 & 7 & 22 & 0.008 & $\mathrm{R}$ & 0.52 & 30 & 7 & $<0.001$ & $\mathrm{~L}$ & -0.62 \\
\hline Marti & 5 & 50 & $<0.001$ & $\mathrm{R}$ & 0.82 & 51 & 3 & $<0.001$ & $\mathrm{~L}$ & -0.89 & 69 & 0 & $<0.001$ & $\mathrm{~L}$ & -1.00 & 49 & 0 & $<0.001$ & $\mathrm{~L}$ & -1.00 \\
\hline Filou & 30 & 49 & 0.042 & $\mathrm{R}$ & 0.24 & 50 & 2 & $<0.001$ & $\mathrm{~L}$ & -0.92 & 48 & 0 & $<0.001$ & $\mathrm{~L}$ & -1.00 & 48 & 0 & $<0.001$ & $\bar{L}$ & -1.00 \\
\hline
\end{tabular}


Left $=$ number of trials performed with the left hand; right $=$ number of trials performed with the right hand; $P=$ probability from the binomial test comparing the number of trials performed with the left or the right hand; bias $=$ hand preference based on the binomial test $(\mathrm{A}=$ ambiguously handed; $\mathrm{L}=$ left-handed; $\mathrm{R}$ = right-handed). 
Table A2. Raw data and individual handedness index (HI) for grasping actions requiring full arm extensions (QHP-Far Grasping task) directed towards item placed at lateral positions

\begin{tabular}{|c|c|c|c|c|c|c|c|c|c|c|c|c|c|c|c|c|c|c|c|c|}
\hline \multirow[b]{2}{*}{ Subject } & \multicolumn{5}{|c|}{ Position LL $\left(-60^{\circ}\right)$} & \multicolumn{5}{|c|}{ Position L $\left(-30^{\circ}\right)$} & \multicolumn{5}{|c|}{ Position R $\left(+30^{\circ}\right)$} & \multicolumn{5}{|c|}{ Position RR $\left(+60^{\circ}\right)$} \\
\hline & Left & Right & $P$ & Bias & $\mathrm{HI}$ & Left & Right & $P$ & Bias & $\mathrm{HI}$ & Left & Right & $P$ & Bias & $\mathrm{HI}$ & Left & Right & $P$ & Bias & $\mathrm{HI}$ \\
\hline \multicolumn{21}{|l|}{ Guenons } \\
\hline Ecureuil & 8 & 52 & $<0.001$ & $\mathrm{R}$ & 0.73 & 47 & 13 & $<0.001$ & $\mathrm{~L}$ & -0.57 & 39 & 21 & 0.027 & $\mathrm{~L}$ & -0.30 & 56 & 4 & $<0.001$ & $\mathrm{~L}$ & -0.87 \\
\hline Chili & 0 & 60 & $<0.001$ & $\mathrm{R}$ & 1.00 & 4 & 56 & $<0.001$ & $\mathrm{R}$ & 0.87 & 18 & 42 & 0.003 & $\mathrm{R}$ & 0.40 & 59 & 1 & $<0.001$ & $\mathrm{~L}$ & -0.97 \\
\hline Amande & 0 & 60 & $<0.001$ & $\mathrm{R}$ & 1.00 & 30 & 30 & 1.000 & A & 0.00 & 49 & 11 & $<0.001$ & $\mathrm{~L}$ & -0.63 & 60 & 0 & $<0.001$ & $\mathrm{~L}$ & -1.00 \\
\hline Chilula & 5 & 55 & $<0.001$ & $\mathrm{R}$ & 0.83 & 22 & 38 & 0.052 & A & 0.27 & 28 & 32 & 0.699 & A & 0.07 & 55 & 5 & $<0.001$ & $\mathrm{~L}$ & -0.83 \\
\hline Tilamook & 0 & 60 & $<0.001$ & $\mathrm{R}$ & 1.00 & 7 & 53 & $<0.001$ & $\mathrm{R}$ & 0.77 & 11 & 49 & $<0.001$ & $\mathrm{R}$ & 0.63 & 58 & 2 & $<0.001$ & $\mathrm{~L}$ & -0.93 \\
\hline Maricopa & 11 & 49 & $<0.001$ & $\mathrm{R}$ & 0.63 & 43 & 17 & 0.001 & $\mathrm{~L}$ & -0.43 & 2 & 58 & $<0.001$ & $\mathrm{R}$ & 0.93 & 43 & 17 & 0.001 & $\mathrm{~L}$ & -0.43 \\
\hline Lowina & 4 & 56 & $<0.001$ & $\mathrm{R}$ & 0.87 & 16 & 44 & $<0.001$ & $\mathrm{R}$ & 0.47 & 12 & 48 & $<0.001$ & $\mathrm{R}$ & 0.60 & 58 & 2 & $<0.001$ & $\mathrm{~L}$ & -0.93 \\
\hline Shawnee & 0 & 60 & $<0.001$ & $\mathrm{R}$ & 1.00 & 7 & 53 & $<0.001$ & $\mathrm{R}$ & 0.77 & 10 & 50 & $<0.001$ & $\mathrm{R}$ & 0.67 & 57 & 3 & $<0.001$ & $\mathrm{~L}$ & -0.90 \\
\hline Plume & 4 & 56 & $<0.001$ & $\mathrm{R}$ & 0.87 & 42 & 18 & 0.003 & $\mathrm{~L}$ & -0.40 & 16 & 44 & $<0.001$ & $\mathrm{R}$ & 0.47 & 29 & 31 & 0.897 & A & 0.03 \\
\hline Lombrik & 2 & 58 & $<0.001$ & $\mathrm{R}$ & 0.93 & 29 & 31 & 0.897 & A & 0.0 & 47 & 13 & $<0.001$ & $\mathrm{~L}$ & -0.57 & 57 & 3 & $<0.001$ & $\mathrm{~L}$ & -0.90 \\
\hline Lowi & 0 & 60 & $<0.001$ & $\mathrm{R}$ & 1.00 & 18 & 42 & $<0.001$ & $\mathrm{R}$ & 0.40 & 52 & 8 & $<0.001$ & $\mathrm{~L}$ & -0.73 & 60 & 0 & $<0.001$ & $\mathrm{~L}$ & -1.00 \\
\hline Arbok & 0 & 60 & $<0.001$ & $\mathrm{R}$ & 1.00 & 3 & 57 & $<0.001$ & $\mathrm{R}$ & 0.90 & 17 & 43 & 0.001 & $\mathrm{R}$ & 0.43 & 60 & 0 & $<0.001$ & $\mathrm{~L}$ & -1.00 \\
\hline \multicolumn{21}{|l|}{ Mangabeys } \\
\hline Lorette & 0 & 60 & $<0.001$ & $\mathrm{R}$ & 1.00 & 5 & 53 & $<0.001$ & $\mathrm{R}$ & 0.83 & 27 & 33 & 0.519 & A & 0.10 & 40 & 20 & 0.013 & $\mathrm{~L}$ & -0.33 \\
\hline & 4 & 56 & $<0.001$ & $\mathrm{R}$ & 0.87 & 2 & 57 & $<0.001$ & $\mathrm{R}$ & 0.9 & 42 & 18 & 0.003 & $\mathrm{~L}$ & -0.40 & 50 & 10 & $<0.001$ & $\overline{\mathrm{L}}$ & -0.67 \\
\hline Chips & 1 & 58 & $<0.001$ & $\mathrm{R}$ & 0.97 & 4 & 56 & $<0.001$ & $\mathrm{R}$ & 0.87 & 55 & 5 & $<0.001$ & $\mathrm{~L}$ & -0.83 & 56 & 4 & $<0.001$ & $\mathrm{~L}$ & -0.87 \\
\hline Juli & 9 & 51 & $<0.001$ & $\mathrm{R}$ & 0.70 & 14 & 46 & $<0.001$ & $\mathrm{R}$ & 0.53 & 49 & 11 & $<0.001$ & $\mathrm{~L}$ & -0.63 & 48 & 12 & $<0.001$ & $\mathrm{~L}$ & -0.60 \\
\hline Bell & 8 & 51 & $<0.001$ & $\mathrm{R}$ & 0.73 & 19 & 40 & 0.009 & $\mathrm{R}$ & 0.3 & 55 & 4 & $<0.001$ & $\mathrm{~L}$ & -0.86 & 59 & 1 & $<0.001$ & $\mathrm{~L}$ & -0.97 \\
\hline Goffrette & 26 & 32 & 0.512 & A & 0.10 & 48 & 12 & $<0.001$ & $\mathrm{~L}$ & -0.60 & 60 & 0 & $<0.001$ & $\mathrm{~L}$ & -1.00 & 59 & 0 & $<0.001$ & $\mathrm{~L}$ & -1.00 \\
\hline Chip & 31 & 26 & 0.597 & A & -0.09 & 34 & 26 & 0.366 & A & -0.13 & 46 & 10 & $<0.001$ & $\mathrm{~L}$ & -0.64 & 44 & 12 & $<0.001$ & $\mathrm{~L}$ & -0.57 \\
\hline Zunie & 5 & 55 & $<0.001$ & $\mathrm{R}$ & 0.83 & 6 & 54 & $<0.001$ & $\mathrm{R}$ & 0.80 & 11 & 49 & $<0.001$ & $\mathrm{R}$ & 0.63 & 12 & 47 & $<0.001$ & $\mathrm{R}$ & 0.59 \\
\hline & 6 & 54 & $<0.001$ & $\mathrm{R}$ & 0.80 & 6 & 54 & $<0.001$ & $\mathrm{R}$ & 0.8 & 56 & 4 & $<0.001$ & $\mathrm{~L}$ & -0.87 & 58 & 1 & $<0.001$ & $\mathrm{~L}$ & -0.97 \\
\hline Len & 1 & 59 & $<0.001$ & $\mathrm{R}$ & 0.97 & 1 & 59 & $<0.001$ & $\mathrm{R}$ & 0.97 & 7 & 53 & $<0.001$ & $\mathrm{R}$ & 0.77 & 21 & 39 & 0.027 & $\mathrm{R}$ & 0.30 \\
\hline George & 8 & 50 & $<0.001$ & $\mathrm{R}$ & 0.72 & 42 & 16 & 0.001 & $\mathrm{~L}$ & -0.45 & 60 & 0 & $<0.001$ & $\mathrm{~L}$ & -1.00 & 57 & 0 & $<0.001$ & $\mathrm{~L}$ & -1.00 \\
\hline Isba & 35 & 24 & 0.193 & A & -0.19 & 39 & 21 & 0.027 & $\mathrm{~L}$ & -0.30 & 57 & 1 & & $\mathrm{~L}$ & -0.97 & 54 & 4 & $<0.001$ & $\mathrm{~L}$ & -0.86 \\
\hline Marti & 59 & 1 & $<0.001$ & $\mathrm{R}$ & -0.97 & 58 & 0 & $<0.001$ & $\overline{\mathrm{L}}$ & -1.00 & 59 & 0 & $<0.001$ & $\mathrm{~L}$ & -1.00 & 57 & 0 & $<0.001$ & $\overline{\mathrm{L}}$ & -1.00 \\
\hline Filou & 6 & 54 & $<0.001$ & $\mathrm{R}$ & 0.80 & 21 & 39 & 0.027 & $\mathrm{R}$ & 0.30 & 45 & 15 & $<0.001$ & $\mathrm{~L}$ & -0.50 & 55 & 5 & $<0.001$ & $\mathrm{~L}$ & -0.83 \\
\hline
\end{tabular}


Left $=$ number of trials performed with the left hand; right $=$ number of trials performed with the right hand; $P=$ probability from the binomial test comparing the number of trials performed with the left or the right hand; bias $=$ hand preference based on the binomial test $(\mathrm{A}=$ ambiguously handed; $\mathrm{L}=$ left-handed; $\mathrm{R}$ = right-handed). 
Table A3. Raw data and individual handedness index (HI) for grasping actions requiring low arm extensions (QHP-Nearby Grasping task) directed towards items placed at lateral positions

\begin{tabular}{|c|c|c|c|c|c|c|c|c|c|c|c|c|c|c|c|c|c|c|c|c|}
\hline \multirow[b]{2}{*}{ Subject } & \multicolumn{5}{|c|}{ Position LL (- 60 $)$} & \multicolumn{5}{|c|}{ Position L $\left(-30^{\circ}\right)$} & \multicolumn{5}{|c|}{ Position R $\left(+30^{\circ}\right)$} & \multicolumn{5}{|c|}{ Position RR $\left(+60^{\circ}\right)$} \\
\hline & Left & Right & $P$ & Bias & $\mathrm{HI}$ & Left & Right & $P$ & Bias & $\mathrm{HI}$ & Left & Right & $P$ & Bias & $\mathrm{HI}$ & Left & Right & $P$ & Bias & $\mathrm{HI}$ \\
\hline \multicolumn{21}{|l|}{ Guenons } \\
\hline Ecureuil & 48 & 12 & $<0.001$ & $\mathrm{~L}$ & -0.60 & 47 & 13 & $<0.001$ & $\mathrm{~L}$ & -0.57 & 33 & 27 & 0.519 & A & -0.10 & 39 & 21 & 0.027 & $\mathrm{~L}$ & -0.30 \\
\hline Chili & 5 & 55 & $<0.001$ & $\mathrm{R}$ & 0.83 & 7 & 53 & $<0.001$ & $\mathrm{R}$ & 0.77 & 3 & 57 & $<0.001$ & $\mathrm{R}$ & 0.90 & 5 & 55 & $<0.001$ & $\mathrm{R}$ & 0.83 \\
\hline Amande & 9 & 51 & $<0.001$ & $\mathrm{R}$ & 0.70 & 14 & 46 & $<0.001$ & $\mathrm{R}$ & & 12 & 48 & $<0.001$ & $\mathrm{R}$ & 0.60 & 10 & 50 & $<0.001$ & $\mathrm{R}$ & 0.67 \\
\hline Chilula & 54 & 6 & $<0.001$ & $\mathrm{~L}$ & -0.80 & 52 & 8 & $<0.001$ & $\mathrm{~L}$ & -0.73 & 28 & 32 & 0.699 & A & 0.07 & 29 & 31 & 0.897 & A & 0.03 \\
\hline Tilamook & 17 & 43 & 0.001 & $\mathrm{R}$ & 0.43 & 13 & 47 & $<0.001$ & $\mathrm{R}$ & 0.57 & 7 & 53 & $<0.001$ & $\mathrm{R}$ & 0.77 & 10 & 50 & $<0.001$ & $\mathrm{R}$ & 0.67 \\
\hline Maricopa & 49 & 11 & $<0.001$ & $\mathrm{~L}$ & -0.63 & 42 & 18 & 0.003 & $\mathrm{~L}$ & -0.40 & 14 & 46 & $<0.001$ & $\mathrm{R}$ & 0.53 & 9 & 51 & $<0.001$ & $\mathrm{R}$ & 0.70 \\
\hline Shawnee & 20 & 40 & 0.013 & $\mathrm{R}$ & 0.33 & 17 & 43 & 0.001 & $\mathrm{R}$ & 0.43 & 8 & 52 & $<0.001$ & $\mathrm{R}$ & 0.73 & 21 & 39 & 0.027 & $\mathrm{R}$ & 0.30 \\
\hline Lowina & 43 & 17 & 0.001 & $\mathrm{~L}$ & -0.43 & 46 & 14 & $<0.001$ & $\mathrm{~L}$ & -0.53 & 31 & 29 & 1.000 & A & -0.03 & 32 & 28 & 1.000 & A & -0.07 \\
\hline Plume & 43 & 17 & 0.001 & $\mathrm{~L}$ & -0.43 & 32 & 28 & 0.699 & $\mathrm{~L}$ & -0.07 & 12 & 48 & $<0.001$ & $\mathrm{R}$ & 0.60 & 10 & 50 & $<0.001$ & $\mathrm{R}$ & 0.67 \\
\hline Lombrik & 40 & 20 & 0.013 & $\mathrm{~L}$ & -0.33 & 43 & 17 & 0.001 & $\mathrm{~L}$ & -0.43 & 38 & 22 & 0.052 & A & -0.27 & 41 & 19 & 0.006 & $\mathrm{~L}$ & -0.37 \\
\hline Lowi & 38 & 22 & 0.052 & A & -0.27 & 37 & 23 & 0.092 & A & -0.23 & 29 & 31 & 0.897 & A & 0.0 & 19 & 41 & 0.006 & $\mathrm{R}$ & 0.37 \\
\hline Arbok & 17 & 43 & 0.001 & $\mathrm{R}$ & 0.43 & 23 & 37 & 0.092 & A & 0.23 & 17 & 43 & 0.001 & $\mathrm{R}$ & 0.43 & 17 & 43 & 0.001 & $\mathrm{R}$ & 0.43 \\
\hline \multicolumn{21}{|l|}{ Mangabeys } \\
\hline Lorette & 1 & 59 & $<0.001$ & $\mathrm{R}$ & 0.97 & 2 & 58 & $<0.001$ & $\mathrm{R}$ & 0.9 & 2 & 58 & $<0.001$ & $\mathrm{R}$ & 0.93 & 0 & 60 & $<0.001$ & $\mathrm{R}$ & 1.00 \\
\hline Many & 35 & 25 & 0.245 & A & -0.17 & 25 & 35 & 0.245 & A & 0.17 & 34 & 26 & 0.366 & A & -0.13 & 42 & 18 & 0.003 & $\mathrm{~L}$ & -0.40 \\
\hline Chipse & 47 & 13 & $<0.001$ & $\mathrm{~L}$ & -0.57 & 42 & 18 & 0.003 & $\mathrm{~L}$ & -0.40 & 42 & 18 & 0.003 & $\mathrm{~L}$ & -0.40 & 52 & 8 & $<0.001$ & $\mathrm{~L}$ & -0.73 \\
\hline Julie & 54 & 6 & $<0.001$ & $\mathrm{~L}$ & -0.80 & 54 & 6 & $<0.001$ & $\mathrm{~L}$ & -0.80 & 42 & 18 & 0.003 & $\mathrm{~L}$ & -0.40 & 32 & 28 & 0.699 & A & -0.07 \\
\hline Bell & 53 & 7 & $<0.001$ & $\mathrm{~L}$ & -0.77 & 48 & 12 & $<0.001$ & $\mathrm{~L}$ & -0.60 & 32 & 28 & 1.000 & A & -0.07 & 16 & 44 & 1.000 & A & 0.47 \\
\hline Goffrette & 59 & 1 & $<0.001$ & $\mathrm{~L}$ & -0.97 & 57 & 3 & $<0.001$ & $\mathrm{~L}$ & -0.90 & 44 & 16 & $<0.001$ & $\mathrm{~L}$ & -0.47 & 38 & 22 & 0.052 & A & -0.27 \\
\hline Chipie & 59 & 1 & $<0.001$ & $\mathrm{~L}$ & -0.97 & 58 & 2 & $<0.001$ & $\mathrm{~L}$ & -0.93 & 37 & 23 & 0.092 & A & -0.23 & 23 & 37 & 0.092 & A & 0.23 \\
\hline Zunie & 40 & 20 & 0.013 & $\mathrm{~L}$ & -0.33 & 16 & 44 & $<0.001$ & $\mathrm{R}$ & 0.47 & 5 & 55 & $<0.001$ & $\mathrm{R}$ & 0.83 & 3 & 57 & $<0.001$ & $\mathrm{R}$ & 0.90 \\
\hline Carillon & 36 & 24 & 0.155 & A & -0.20 & 26 & 34 & 0.366 & A & 0.13 & 10 & 50 & $<0.001$ & $\mathrm{R}$ & 0.67 & 10 & 50 & $<0.001$ & $\mathrm{R}$ & 0.67 \\
\hline Lenni & 51 & 9 & $<0.001$ & $\mathrm{~L}$ & -0.70 & 50 & 10 & $<0.001$ & $\mathrm{~L}$ & -0.67 & 25 & 35 & 0.245 & A & 0.17 & 21 & 39 & 0.027 & $\mathrm{R}$ & 0.30 \\
\hline
\end{tabular}




$\begin{array}{lcccccccccccccccccccc}\text { George } & 60 & 0 & <0.001 & \mathrm{~L} & -1.00 & 60 & 0 & <0.001 & \mathrm{~L} & -1.00 & 60 & 0 & <0.001 & \mathrm{~L} & -1.00 & 58 & 2 & <0.001 & \mathrm{~L} & -0.93 \\ \text { Isba } & 57 & 3 & <0.001 & \mathrm{~L} & -0.90 & 54 & 6 & <0.001 & \mathrm{~L} & -0.80 & 20 & 40 & 0.013 & \mathrm{R} & 0.33 & 11 & 49 & <0.001 & \mathrm{R} & 0.63 \\ \text { Marti } & 59 & 1 & <0.001 & \mathrm{~L} & -0.97 & 59 & 1 & <0.001 & \mathrm{~L} & -0.97 & 58 & 2 & <0.001 & \mathrm{~L} & -0.93 & 50 & 10 & <0.001 & \mathrm{~L} & -0.67 \\ \text { Filou } & 2 & 58 & <0.001 & \mathrm{R} & 0.93 & 0 & 60 & <0.001 & \mathrm{R} & 1.00 & 0 & 60 & <0.001 & \mathrm{R} & 1.00 & 1 & 59 & <0.001 & \mathrm{R} & 0.97 \\ \text { Pirate } & 60 & 0 & <0.001 & \mathrm{~L} & -1.00 & 60 & 0 & <0.001 & \mathrm{~L} & -1.00 & 60 & 0 & <0.001 & \mathrm{~L} & -1.00 & 60 & 0 & <0.001 & \mathrm{~L} & -1.00 \\ \text { Rapide } & 59 & 1 & <0.001 & \mathrm{~L} & -0.97 & 60 & 0 & <0.001 & \mathrm{~L} & -1.00 & 60 & 0 & <0.001 & \mathrm{~L} & -1.00 & 60 & 0 & <0.001 & \mathrm{~L} & -1.00\end{array}$

Left $=$ number of trials performed with the left hand; Right $=$ number of trials performed with the right hand; $P=$ probability from the binomial test comparing the number of trials performed with the left or the right hand; bias $=$ hand preference based on the binomial test $(\mathrm{A}=$ ambiguously handed; $\mathrm{L}=$ left-handed; $\mathrm{R}$ = right-handed). 


\section{Figure captions}

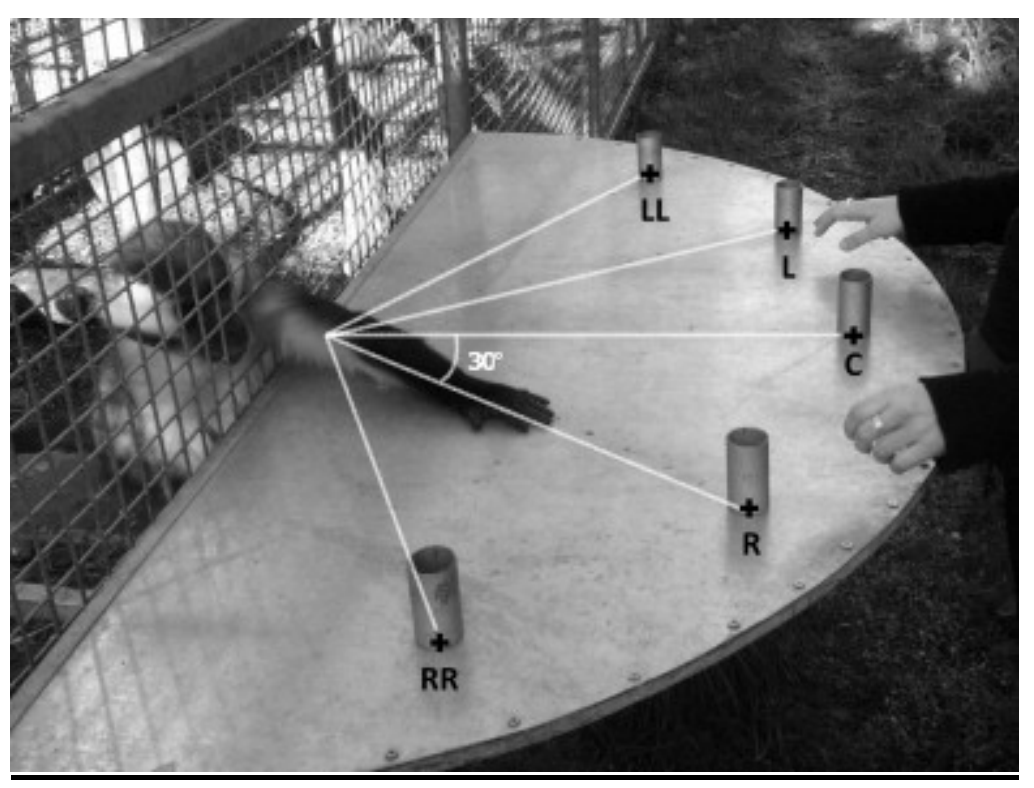

Figure 1. Experimental design for the QHP-Pointing task. Marti, an adult male mangabey, sitting on the stool attached onto the cage mesh, produces a left-handed pointing gesture directed towards the tube located in the position $\mathrm{R}\left(+30^{\circ}\right.$ from the midline) by extending the left arm through the rectangular opening cut in the cage mesh.

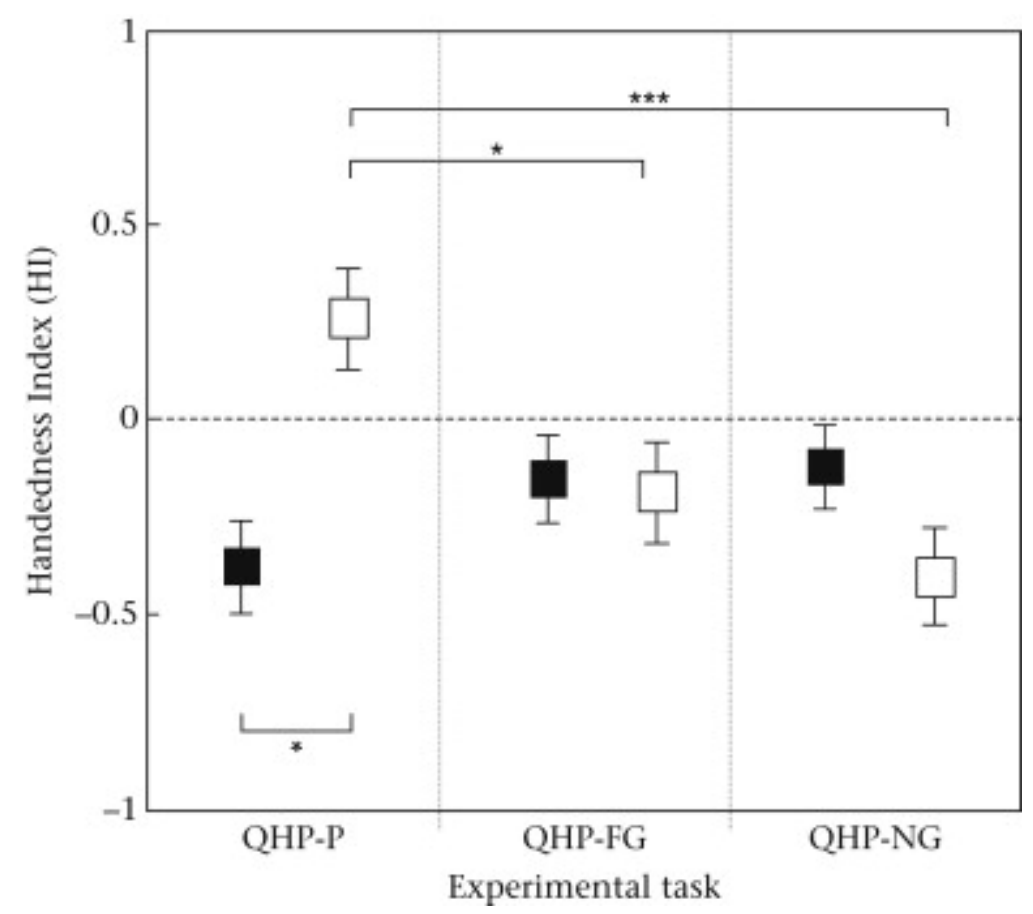

Figure 2. Handedness index (HI) for the three experimental tasks in mangabeys. Presented values are the means $\pm \mathrm{SE}$ for heterogeneous pointers (black squares) and homogeneous 
pointers (white squares) in the QHP-Pointing (QHP-P), the QHP-Far Grasping (QHP-FG) and the QHP-Nearby Grasping (QHP-NG) tasks. FDR-adjusted $P$ values from paired $t$ tests: $* P<$ $0.05 ; * * * P<0.001(\mathrm{FDR}=$ false discovery rate $)$

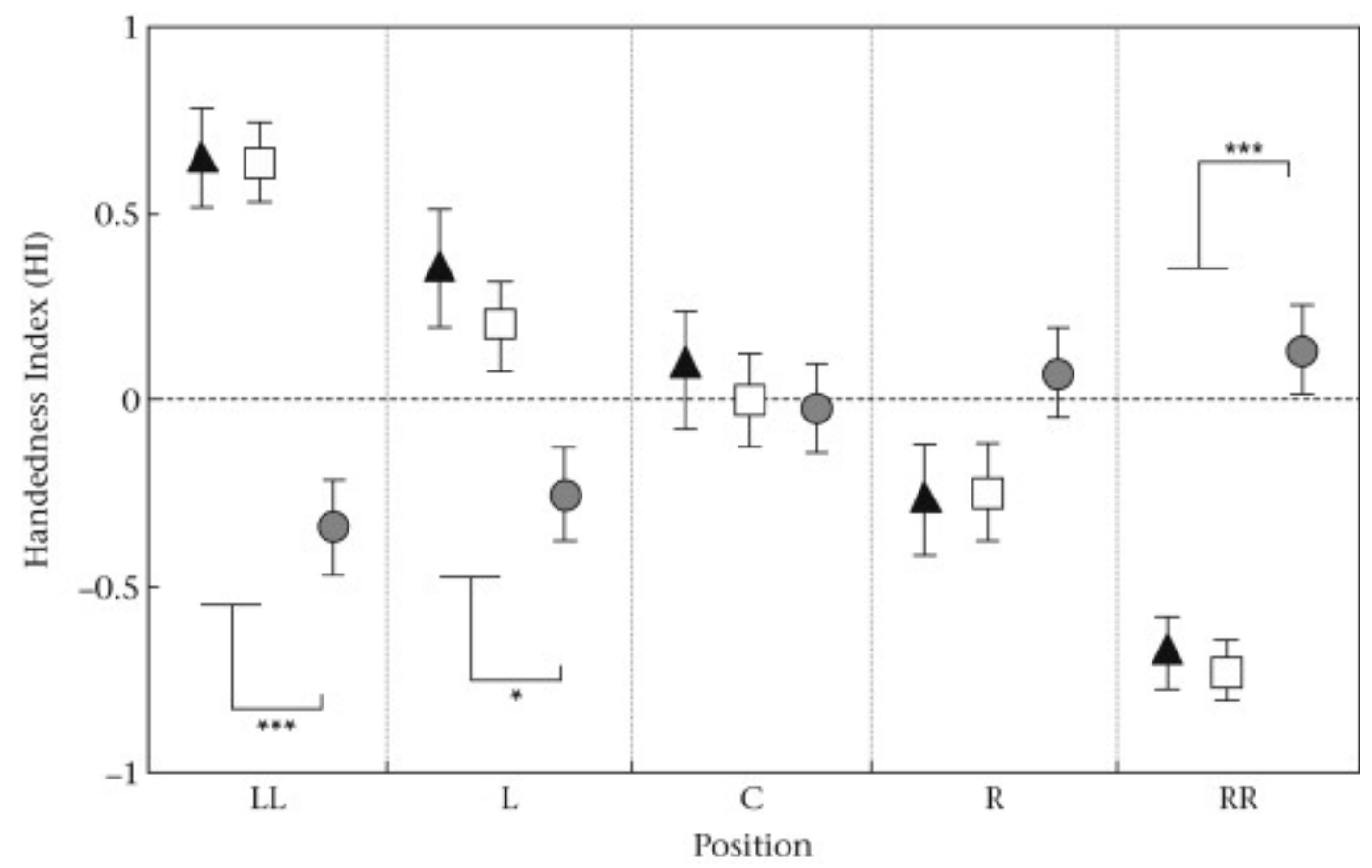

Figure 3. Handedness index $(\mathrm{HI})$ at each position and for the three experimental tasks in guenons and mangabeys. Presented values are the means \pm SE for the QHP-Pointing task (black triangles), the QHP-Far Grasping task (white squares) and the QHP-Nearby Grasping task (grey circles) at positions LL $\left(-60^{\circ}\right), \mathrm{L}\left(-30^{\circ}\right), \mathrm{C}\left(0^{\circ}\right), \mathrm{R}\left(+30^{\circ}\right)$ and $\mathrm{RR}\left(+60^{\circ}\right)$. FDRadjusted $P$ values from paired $t$ tests: $* P<0.05 ; * * * P<0.001$ (FDR $=$ false discovery rate). 